\title{
Pre-operative traction for hip fractures in adults (Review)
}

\author{
Handoll HHG, Queally JM, Parker MJ
}

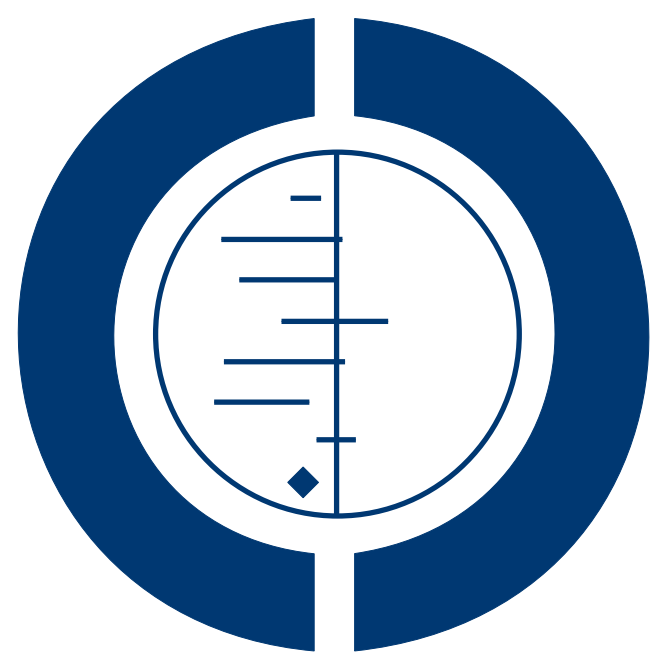

\section{THE COCHRANE COLLABORATION $^{\circledR}$}

This is a reprint of a Cochrane review, prepared and maintained by The Cochrane Collaboration and published in The Cochrane Library 2011, Issue 12

http://www.thecochranelibrary.com

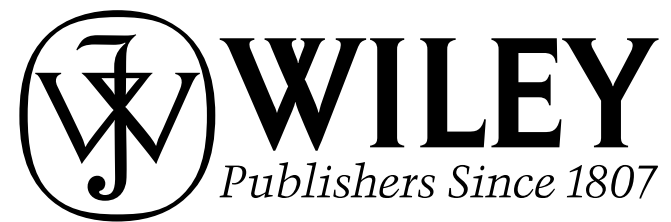

Pre-operative traction for hip fractures in adults (Review)

Copyright (c) 20II The Cochrane Collaboration. Published by John Wiley \& Sons, Ltd. 
TABLE OF CONTENTS

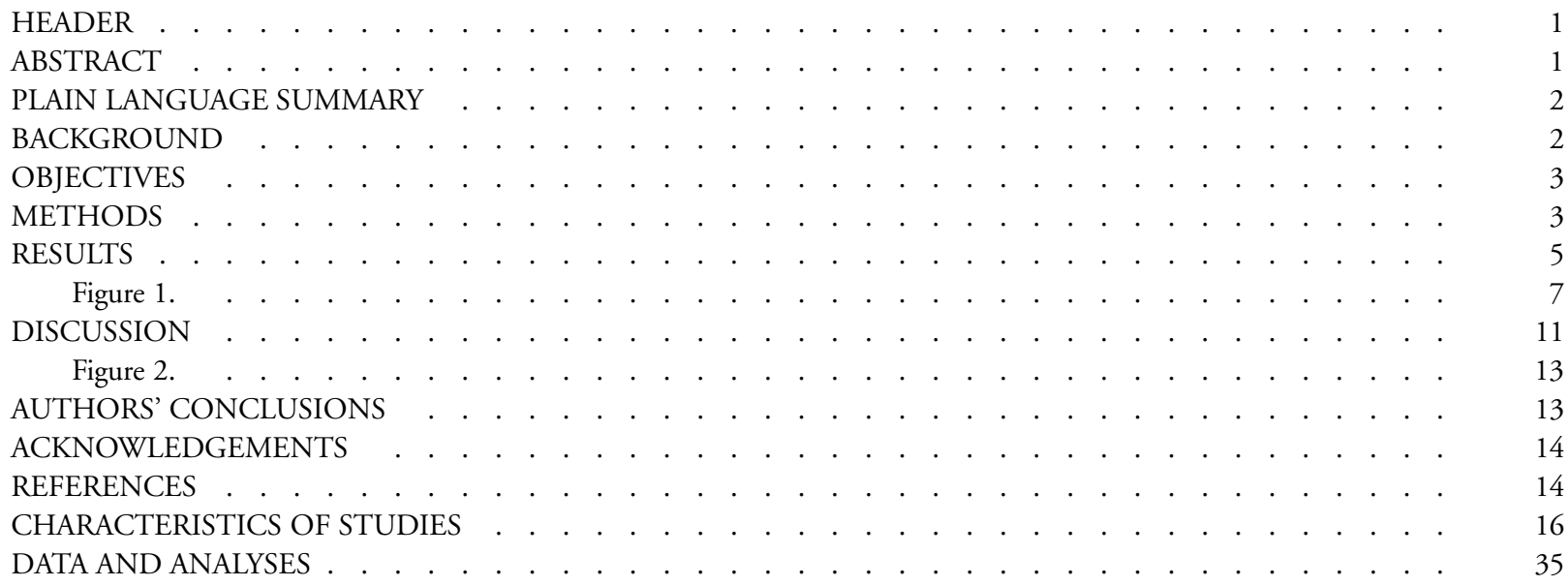

Analysis 1.1. Comparison 1 Pre-operative traction versus no traction, Outcome 1 Pain (Visual Analogue Scale: 0: none to 10: worst imaginable). . . . . . . . . . . . . . . . . . . . . . . . . . . . . . . . 37

Analysis 1.2. Comparison 1 Pre-operative traction versus no traction, Outcome 2 Analgesic use on ward (participants). 38 Analysis 1.3. Comparison 1 Pre-operative traction versus no traction, Outcome 3 Analgesic use on ward (doses / injections). . . . . . . . . . . . . . . . . . . . . . . . . . . . . . . . . . . . 38 Analysis 1.4. Comparison 1 Pre-operative traction versus no traction, Outcome 4 Pressure sores. $\quad . \quad$. . . . . . . 39 Analysis 1.5. Comparison 1 Pre-operative traction versus no traction, Outcome 5 Difficulty in fracture reduction. $\quad . \quad 39$ Analysis 1.6. Comparison 1 Pre-operative traction versus no traction, Outcome 6 Poor quality fracture reduction. $\quad . \quad 40$ Analysis 1.7. Comparison 1 Pre-operative traction versus no traction, Outcome 7 General complications. . . . . $\quad 40$ Analysis 1.8. Comparison 1 Pre-operative traction versus no traction, Outcome 8 Fracture fixation failure. . . . . 41 Analysis 1.9. Comparison 1 Pre-operative traction versus no traction, Outcome 9 Length of operation (minutes). . $\quad . \quad 41$ Analysis 1.10. Comparison 1 Pre-operative traction versus no traction, Outcome 10 Intra-operative blood loss (ml). . 42 Analysis 1.11. Comparison 1 Pre-operative traction versus no traction, Outcome 11 Length of hospital stay (days). $\quad . \quad 42$ Analysis 2.1. Comparison 2 Traction versus no or 'placebo' traction, Outcome 1 Pain (VAS) - soon after immobilisation. 43 Analysis 2.2. Comparison 2 Traction versus no or 'placebo' traction, Outcome 2 Pain (VAS) - at 12 hours. . . . . . 43 Analysis 2.3. Comparison 2 Traction versus no or 'placebo' traction, Outcome 3 Analgesic use - injections / day. . . 44 Analysis 3.1. Comparison 3 Skin traction versus skeletal traction, Outcome 1 Pain soon after traction (Visual Analogue Scale: 0: none to 10: worst imaginable).

Analysis 3.2. Comparison 3 Skin traction versus skeletal traction, Outcome 2 Analgesic use on ward (number of doses). Analysis 3.3. Comparison 3 Skin traction versus skeletal traction, Outcome 3 Length of surgery (minutes). . . . . APPENDICES . . . . . . . . . . . . . . . . . . . . . . . . . . . . . 45 WHAT'S NEW . . . . . . . . . . . . . . . . . . . . . . . . . . . . . . . . . . . . . 48 HISTORY . . . . . . . . . . . . . . . . . . . . . . . . . . . . . . . . . . . . . . . 48 CONTRIBUTIONS OF AUTHORS . . . . . . . . . . . . . . . . . . . . . . . . . . . . . . 50 DECLARATIONS OF INTEREST . . . . . . . . . . . . . . . . . . . . . . . . . . . . . . 50 SOURCES OF SUPPORT . . . . . . . . . . . . . . . . . . . . . . . . . . . . . . . . . . . . . . . . . 50 DIFFERENCES BETWEEN PROTOCOL AND REVIEW . . . . . . . . . . . . . . . . . . . . . 50 INDEX TERMS . . . . . . . . . . . . . . . . . . . . . . . . . . . . . . . . . . . . 50 


\title{
[Intervention Review]
}

\section{Pre-operative traction for hip fractures in adults}

\author{
Helen HG Handoll ${ }^{1}$, Joseph M Queally ${ }^{2}$, Martyn J Parker ${ }^{3}$ \\ ${ }^{1}$ Health and Social Care Institute, Teesside University, Middlesborough, UK. ${ }^{2}$ Higher Surgical Training Group, Royal College of \\ Surgeons in Ireland, Dublin, Ireland. ${ }^{3}$ Department of Orthopaedics, Peterborough and Stamford Hospitals NHS Foundation Trust, \\ Peterborough, UK \\ Contact address: Helen HG Handoll, Health and Social Care Institute, Teesside University, Middlesborough, Tees Valley, TS1 3BA, \\ UK. h.handoll@tees.ac.uk.H.Handoll@ed.ac.uk.
}

Editorial group: Cochrane Bone, Joint and Muscle Trauma Group.

Publication status and date: New search for studies and content updated (conclusions changed), published in Issue 12, 2011.

Review content assessed as up-to-date: 1 July 2011.

Citation: Handoll HHG, Queally JM, Parker MJ. Pre-operative traction for hip fractures in adults. Cochrane Database of Systematic Reviews 2011, Issue 12. Art. No.: CD000168. DOI: 10.1002/14651858.CD000168.pub3.

Copyright (C) 2011 The Cochrane Collaboration. Published by John Wiley \& Sons, Ltd.

\begin{abstract}
A B S T R A C T
Background

Following a hip fracture, traction may be applied to the injured limb before surgery. This is an update of a Cochrane review first published in 1997, and previously updated in 2006.
\end{abstract}

\section{Objectives}

To evaluate the effects of traction applied to the injured limb prior to surgery for a fractured hip. Different methods of applying traction (skin or skeletal) were considered.

\section{Search methods}

We searched the Cochrane Bone, Joint and Muscle Trauma Group Specialised Register (April 2011), the Cochrane Central Register of Controlled Trials (in The Cochrane Library 2011, Issue 4), MEDLINE (1948 to April week 2 2011), EMBASE (1980 to 2011 week 16), and CINAHL (1982 to 1 April 2011), conference proceedings, trials registries and reference lists of articles.

\section{Selection criteria}

All randomised or quasi-randomised trials comparing either skin or skeletal traction with no traction, or skin with skeletal traction for patients with an acute hip fracture prior to surgery.

\section{Data collection and analysis}

At least two authors independently assessed trial quality and extracted data. Additional information was sought from all trialists. Wherever appropriate and possible, data were pooled.

\section{Main results}

One new trial was included in this update. In all, 11 trials (six were randomised and five were quasi-randomised), involving a total of 1654 predominantly elderly patients with hip fractures, are included in the review. Most trials were at risk of bias, particularly that resulting from inadequate allocation concealment, lack of assessor blinding and incomplete outcome assessment. Only very limited data pooling was possible.

Ten trials compared predominantly skin traction with no traction. The available data provided no evidence of benefit from traction either in the relief of pain (pain soon after immobilisation (visual analogue score 0: none to 10: worst pain): mean difference $0.11,95 \%$ 
CI -0.27 to $0.50 ; 3$ trials), ease of fracture reduction or quality of fracture reduction at time of surgery. There were inconclusive data for pressures sores and other complications, including fracture fixation failure. Three minor adverse effects (sensory disturbance and skin blisters) related to skin traction were reported.

One of the above trials included both skin and skeletal traction groups. This trial and one other compared skeletal traction with skin traction and found no important differences between these two methods, although the initial application of skeletal traction was noted as being more painful and more costly.

\section{Authors' conclusions}

From the evidence available, the routine use of traction (either skin or skeletal) prior to surgery for a hip fracture does not appear to have any benefit. However, the evidence is also insufficient to rule out the potential advantages for traction, in particular for specific fracture types, or to confirm additional complications due to traction use.

Given the increasing lack of evidence for the use of pre-operative traction, the onus should now be on clinicians who persist in using pre-operative traction to either stop using it or to use it only in the context of a well-designed randomised controlled trial.

\section{PLAIN LANGUAGESUMMARY}

\section{The routine use of traction before surgery in adults with hip fracture}

For people with hip fractures, traction involves either using tapes (skin traction) or pins (skeletal traction) attached to the injured leg and connected to weights via a pulley. The application of traction before surgery is thought to relieve pain and make the subsequent surgery easier. Where traction is not used, the injured limb is usually placed on a pillow and the patient encouraged to adopt a position of greatest comfort.

This review summarising the evidence from randomised controlled trials included 11 trials with 1654 participants. Consistent with the general hip fracture population, most of the trial participants were older persons of around 80 years of age and the majority were female. Ten trials compared traction versus no traction and two trials, including one of the preceding 10 trials, compared skin and skeletal traction. As well as limitations in the trial methods, there were very limited data for pooling and a lack of information about the longer-term consequences of applying or not applying traction. Nonetheless, the evidence from the 10 trials consistently showed no evidence to support the supposed advantages of traction described above. There were inconclusive data for pressures sores (skin ulcers) and other complications. One trial reported three adverse effects (sensory disturbance and skin blisters) related to skin traction; all were minor.

\section{B A C K G R O U N D}

\section{Description of the condition}

Fractures of the proximal femur encompass intracapsular (femoral neck) and extracapsular (trochanteric and subtrochanteric) fractures of the hip. They occur predominantly in older people (aged over 65 years), especially women. The incidence of hip fracture varies considerably between different populations (Bjorgul 2007; Koh 2001). An incidence rate of 1024 per 100,000 for women over 50 and 452 per 100,000 for men over 50 was reported for Norway between 1998 and 2003 (Bjorgul 2007). The absolute incidence of hip fractures is increasing due to an ageing popula- tion (Bergstrom 2009; Kannus 1996). Hip fractures are associated with significant mortality with mortality rates of up to $37 \%$ within the first year after fracture reported (Lyons 1997). Additionally, hip fractures are associated with significant morbidity with many older patients never returning to their home environment. The economic burden associated with these fractures is substantial due to the cost of the initial acute hospital admission and the subsequent rehabilitation or provision of long term residential care (Haentjens 2005). There has been a concerted effort to improve the outcome of hip fracture treatment with an emphasis on early surgery and multidisciplinary management by both orthopaedic and geriatric teams from the initial time of admission to hospital (Moran 2010). 
At the time of fracture, the fracture ends may be displaced relative to each other or are at risk of displacing due to muscle forces acting across the hip. A displaced fracture causes pain, makes reduction difficult and puts the patient at an increased risk of complications such as fracture non-union, avascular necrosis and nerve injury.

\section{Description of the intervention}

It has been, and in some places remains, standard orthopaedic practice to apply skeletal or skin traction to the injured limb following an acute hip fracture, prior to surgery (Billsten 1996; Brink 2005). Traction may be either 'skin' or 'skeletal'. Skin traction may be applied by way of adhesive tape, tapes bandaged to the limb or a traction boot. Skeletal traction involves passing a metal pin through the proximal tibia or distal femur, under local or general anaesthesia. Traction is then applied using ropes and weights attached to the end of the tapes or pin.

\section{How the intervention might work}

The main theoretical advantages that are advocated for traction are that it will reduce pain at the fracture site and assist the reduction of the fracture thereby making the subsequent operation easier to perform. For intracapsular fractures further advantages of traction have been proposed in the reduction of circulatory complications. Firstly, traction may reduce any tamponade effect (pressure caused by the build up of excess fluid that acts to compress blood vessels and block blood flow) within the joint (Maruenda 1997). Secondly, it may reduce the movement at the fracture surfaces and deformity at the fracture site. Either effect proposed for traction might reduce the risk of obstruction of, or damage to the tenuous blood supply to the femoral head via the retinacular vessels. It has been postulated that this might lead to a reduction in the incidence of non-union or avascular necrosis (also termed osteonecrosis) for those fractures treated by internal fixation, however clinical evidence to support this is lacking.

Traction does, however, have potential disadvantages. It makes nursing of the patient more difficult: for example, in lifting the patient onto a bedpan or in pressure area care prior to surgery. Other possible adverse effects of skin traction are damage to the skin by mechanical shearing (Shabat 2002), ischaemia to the limb from tight bandages or allergy to adhesive strapping. If skeletal traction is used with a tibial pin the application of this can be uncomfortable, with the occasional complication of sepsis at the pin site. Furthermore, clinical studies have suggested that slight flexion, abduction and external rotation of the hip results in the lowest intracapsular pressure (Stromqvist 1988). Traction with the hip in extension may thereby increase intracapsular pressure (Svalastoga 1989), although this may not apply for traction with the hip in the position described in the previous sentence (Maruenda 1997).

\section{Why it is important to do this review}

Over several years and seven updates this review has continued to show a lack of benefit of pre-operative traction for fractures of the proximal fracture (Parker 2006). However, while the findings from the trials have been consistent, the available evidence has been from trials with sub-optimal and flawed methodology. Despite this lack of demonstrable benefit, traction continues to be used as standard treatment in some centres (Kemler 2006; Lindholm 2008). More recent studies have pointed to increased complications associated with traction (Kemler 2006; Lindholm 2008). Inadequate evidence, variation in practice and the potential for traction to be less benign than previously thought warrant the updating of this review.

\section{O B J E C T I V E S}

We aimed to evaluate the effects (benefits and harms) of pre-operative traction to the injured limb following an acute fracture of the proximal femur in adults. We compared the relative effects of traction versus no traction; and skin versus skeletal traction. We considered these effects primarily in terms of pain relief and pressure sores.

\section{METHODS}

\section{Criteria for considering studies for this review}

\section{Types of studies}

All randomised or quasi-randomised (i.e. those trials which allocated participants to an intervention using methods that are not strictly random such as those based on hospital record number, dates of birth and alternation) controlled trials comparing traction versus no traction, or different types of traction, for patients with an acute fracture of the proximal femur were considered.

\section{Types of participants}

Skeletally mature patients with a proximal femoral fracture for whom surgery is indicated.

\section{Types of interventions}

Application of skin or skeletal traction to the injured limb prior to surgery. Traction was compared with no traction, where the patient is nursed 'free in bed', often with the injured limb being placed on a pillow. Skin versus skeletal traction were also compared. 


\section{Types of outcome measures}

Data for the following outcome measures were collected where available.

\section{Primary outcomes}

- Pain (visual analogue scale) or analgesia use prior to surgery

- Incidence of pressure sores (also termed pressure ulcers). There are many different pressure sore/ulcer classification systems in use. Typically, the higher the grade the more severe the damage to the tissues. Grade 1 generally represents reddened but unbroken skin (erythema).

\section{Secondary outcomes}

- Ease of fracture reduction (subjective assessment by surgeon) or time taken to reduce fracture

- Incidence of medical complications: thromboembolic complications and 'other', as specified in trial reports

- Incidence of adverse events directly or putatively related to treatment, including sciatic nerve palsy

- Incidence of fracture healing complications: fracture nonunion; avascular necrosis (also called osteonecrosis: aseptic necrosis of bone); and 'other' as specified in trial reports (long term: 6 months or more)

- Mortality (long term: 6 months of more)

While data for these outcomes were collected, these were not intended for the summary of findings tables

- Length of surgery

- Intra-operative blood loss

- Patient satisfaction

\section{Search methods for identification of studies}

\section{Electronic searches}

We searched the Cochrane Bone, Joint and Muscle Trauma Group Specialised Register (April 2011), the Cochrane Central Register of Controlled Trials (in The Cochrane Library 2011, Issue 4), MEDLINE (1948 to April week 2 2011), EMBASE (1980 to 2011 week 16), and CINAHL (1982 to 1 April 2011). The search strategies for the Cochrane Central Register of Controlled Trials, MEDLINE, EMBASE and CINAHL are shown in Appendix 2. The subject specific search for MEDLINE was combined with all three stages of the optimal trial search strategy (Higgins 2005). Details of the search strategies used up to March 2006 for previous versions of the review are given in Parker 2006. No language or publication restrictions were applied.

On 25 April 2011, we searched the American Orthopaedic Trauma Association annual meetings (1996 to 2010) using term "traction", and the conference proceedings (2002 to 2011) of the Journal of Bone and Joint Surgery - British Volume (JBJS-Br) using the term "traction" in the title.

Using the terms "traction and fracture*", we searched the WHO International Clinical Trials Registry Platform

Search Portal (April 2011) and Current Controlled Trials (April 2011) for ongoing and recently completed trials.

\section{Searching other resources}

We searched our own reference databases and reference lists of articles.

\section{Data collection and analysis}

\section{Selection of studies}

Copies of all studies identified as eligible were obtained and scrutinised by all review authors listed on the bylines for successive versions of this review.

\section{Data extraction and management}

Data for the outcomes listed above were extracted from trial reports by two authors (HH and MJP) for trials included up to the 2006 update and subsequently from the newly included trial report by all three authors. Any disagreement was resolved by discussion. All trialists were approached for further information on outcomes and trial methodology.

\section{Assessment of risk of bias in included studies}

Risk of bias was independently assessed by two authors (JQ and $\mathrm{HH}$ ) for previously included trials and by all three authors for the newly included trial. There was no masking of authors or sources. We used the risk of bias tool outlined in the Cochrane Handbook for Systematic Reviews of Interventions (Higgins 2008a). This tool incorporates assessment of randomisation (sequence generation and allocation concealment), blinding (of participants, treatment providers and outcome assessors), completeness of outcome data, selection of outcomes reported and other sources of bias. We considered subjective and objective outcomes separately in our assessment of blinding and short-term outcomes (measured up to and including surgery) and longer-term (post-operative) outcomes for completeness of outcome data. We assessed two additional sources of bias: selection bias resulting from major imbalances in key baseline characteristics (age, sex, previous mobility, fracture type, previous residence); and performance bias resulting from lack of comparability in the experience of care providers and provision of treatment interventions such as pre-operative pain relief and timing of surgery. Any differences were resolved through discussion. 


\section{Measures of treatment effect}

For individual trials, we report risk ratios (RR) with $95 \%$ confidence intervals for dichotomous outcomes, and mean differences (MD) and 95\% confidence intervals for continuous outcomes.

\section{Unit of analysis issues}

We considered, where relevant, possible unit of analysis issues relating to the use of cluster randomisation, inclusion of people with bilateral fractures, and reporting of results by summation of the incidence of total outcomes, such as overall complications, rather than people with outcomes where a trial participant can have more than one outcome, and outcomes at multiple time points.

\section{Dealing with missing data}

We contacted trialists for missing information, including for denominators and standard deviations. We performed intention-totreat analyses where possible. We did not impute missing standard deviations.

\section{Assessment of heterogeneity}

Heterogeneity between comparable trials was assessed by visual inspection of the forest plot along with consideration of the chi $^{2}$ test for heterogeneity and the $\mathrm{I}^{2}$ statistic (Higgins 2003).

\section{Assessment of reporting biases}

There are insufficient data thus far to merit the production of funnel plots to explore publication bias. The search for trials via conference proceedings and trial registration, and information gained from the contacting of trial authors, have provided some insights on trial publication.

\section{Data synthesis}

Results of comparable groups of trials were pooled using the fixedeffect model. If we had decided to pool the results in the light of statistically significant heterogeneity $\left(\mathrm{chi}^{2}<0.10\right)$ or substantial inconsistency $\left(\mathrm{I}^{2}>50 \%\right)$, we planned to check the results when a random-effects model was used.

\section{Subgroup analysis and investigation of heterogeneity}

No subgroup analyses were specified a priori. For this update (issue $\mathrm{xx}, 2011$ ), we established two subgroups: by type of fracture (initially, intracapsular versus extracapsular) and gender. To test whether the subgroups are statistically significantly different from one another, we planned to test the interaction using the technique outlined by Altman 2003 .

\section{Sensitivity analysis}

We planned sensitivity analyses based on aspects of trial methodology: specifically, the risk of bias associated with inadequate concealment of allocation; and to explore the effects of missing data, particularly for dichotomous outcomes.

\section{R E S U L T S}

\section{Description of studies}

See: Characteristics of included studies.

\section{Results of the search}

Updating the search to April 2011 resulted in the identification of only one new trial (Saygi 2010), which was included. Search results of the individual databases were: CENTRAL (46), MEDLINE (36), EMBASE (78), CINAHL (253), Orthopaedic Trauma Association abstracts (69), Journal of Bone and Joint Surgery British Volume conference proceedings (36), WHO trials register (5), Current Controlled Trials (12).

All 11 of the randomised or quasi-randomised controlled trials so far identified were included in this review. The subject-specific MEDLINE database search revealed four full published articles (Anderson 1993; Finsen 1992; Needoff 1993; Saygi 2010). Handsearching of journals identified the five conference abstracts related to these studies, including the study of Jerre 2000, and the full publications of Jerre 2000 and Resch 1998, previously available only as conference abstracts. Draper 1997 was identified via the UK National Research Register. On contacting the lead author, an internal report and a reference to the published trial report were obtained. The published trial report was only indexed in CINAHL in May 2000. Rosen 2001 was located simultaneously by prospective journal searching and searching the specialised register. Ghnaimat 2005, Resch 2005 and Yip 2002 were located via EMBASE

\section{Included studies}

Details of individual trials are given in the Characteristics of included studies.

\section{Design}

Of the 11 included trials, six were randomised and the other five (Anderson 1993; Ghnaimat 2005; Needoff 1993; Saygi 2010; Yip 2002) were quasi-randomised. 


\section{Sample sizes}

The 11 included trials involved a total of 1654 patients admitted into hospital with proximal femur fractures. Study size ranged from 67 (Needoff 1993) to 311 (Yip 2002).

\section{Setting}

Ten included trials were single centre studies conducted in one of seven countries: China (1 trial); Jordan (1 trial); Norway (1 trial); Sweden (3 trials); United Kingdom (3 trials); United States ( 1 trial). The remaining trial (Saygi 2010) was carried out at two different hospitals in Turkey. Details of the timing of study recruitment were provided for four trials (Anderson 1993; Ghnaimat 2005; Rosen 2001; Yip 2002). The earliest published trial was Finsen 1992.

\section{Participants}

The majority of participants in each trial were women: 57\% (Ghnaimat 2005) to $85 \%$ (Draper 1997) of the trial population. The mean age of trial participants in individual trials ranged between 73 years (Ghnaimat 2005) and 81 years (Anderson 1993; Resch 1998; Rosen 2001). All trials included intracapsular and extracapsular hip fractures. The proportion of intracapsular fractures varied from 19\% (Ghnaimat 2005) to 58\% (Finsen 1992). Intracapsular fracture displacement was recorded in two trials (Jerre 2000; Saygi 2010) with the majority of fractures being displaced according to the Garden classification system. Five trials (Anderson 1993; Draper 1997; Ghnaimat 2005; Resch 1998, Resch 2005) explicitly mentioned the exclusion of patients who were unable to tolerate traction, such as those with skin ulcers. Five trials (Anderson 1993; Needoff 1993; Rosen 2001; Saygi 2010; Yip 2002) excluded patients with dementia or cognitive impairment.

\section{Interventions}

Ten studies (Anderson 1993; Draper 1997; Finsen 1992; Ghnaimat 2005; Jerre 2000; Needoff 1993; Resch 2005; Rosen 2001; Saygi 2010; Yip 2002) compared traction with no traction, and two studies (Finsen 1992; Resch 1998) compared skin with skeletal traction. Resch 2005 had two non-traction groups, one involving placement of the injured limb in a specially designed foam pillow and the other where an ordinary pillow was placed under the hip of the injured limb. Saygi 2010 had two control groups, one involving skin traction device without the use of weights and a pillow beneath the injured limb and the other where only a pillow was placed beneath the injured limb.

\section{Outcomes}

The follow-up period included the operation in all studies except Rosen 2001, where participants were followed up until surgery, and Saygi 2010, where the duration of follow-up was 12 hours for pain and unclear for monitoring complications. Anderson 1993 and Ghnaimat 2005 exceeded this by recording the length of hospital stay; Resch 1998 and Resch 2005 monitored complications such as infection and oedema on the ward for three to four days after the operation; and Draper 1997 assessed pressure sores daily up to the seventh post-operative day. Jerre 2000 was the only study to follow up trial participants after discharge, but even then the length of follow-up was only four months. Yip 2002 claimed a follow-up of one year, though only data up to one week from admission were provided.

All 11 trials assessed pain using a visual analogue scale or by recording analgesic use, or both. Seven trials (Anderson 1993; Draper 1997; Ghnaimat 2005; Jerre 2000; Needoff 1993; Saygi 2010; Yip 2002) reported pressure sores. There was no description of the grade of pressure sore in either Needoff 1993 or Saygi 2010. Other outcomes reported by the included trials were ease of fracture reduction, medical complications, complications directly or putatively related to traction, fracture healing complications, mortality, length of surgery, intra-operative blood loss, and length of hospital stay.

\section{Additional information from trial authors}

Further details, particularly to enable data analysis, were sought from the authors of all the trials. Replies from Finsen 1992 and Needoff 1993 produced no or only limited new information. This reflected the regrettable loss of access to the original data. Jerre 2000 provided supplementary information which included a draft trial report. As well as providing the internal report of his study, Draper 1997 provided some other details of trial methodology. Resch (Resch 1998; Resch 2005) and the authors of Rosen 2001 and Yip 2002 provided further details of trial methodology. Additional results were also provided for Resch 2005 and Yip 2002.

\section{Risk of bias in included studies}

The risk of bias judgements on nine items for the individual trials are summarised in Figure 1 and described in the risk of bias tables in the Characteristics of included studies. 
Figure I. Risk of bias summary: review authors' judgements about each risk of bias item for each included study.

\begin{tabular}{|c|c|c|c|c|c|c|c|c|c|}
\hline & 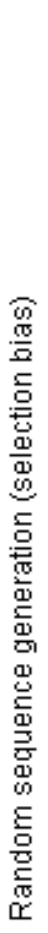 & 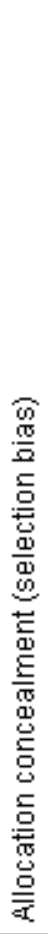 & 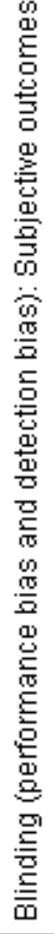 & 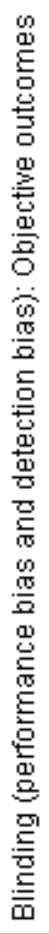 & 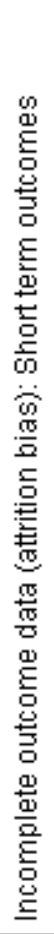 & 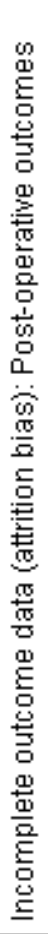 & 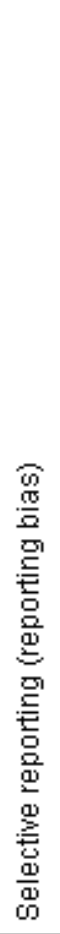 & 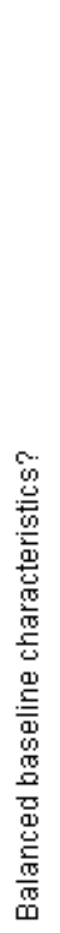 & 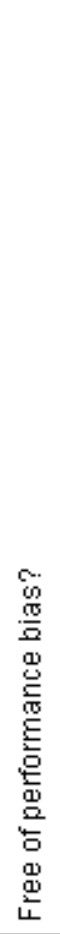 \\
\hline Anderson 1993 & & & & + & $?$ & $?$ & - & $?$ & + \\
\hline Draper 1997 & + & & 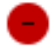 & $?$ & & & $?$ & - & $?$ \\
\hline Finsen 1992 & 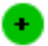 & $?$ & 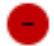 & $?$ & & $?$ & - & $?$ & $?$ \\
\hline Ghnaimat 2005 & & & & + & & & & + & $?$ \\
\hline Jerre 2000 & $?$ & + & & $?$ & 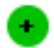 & + & $?$ & $?$ & + \\
\hline Needoff 1993 & & & & $?$ & & & & $?$ & + \\
\hline Resch 1998 & $?$ & $?$ & & $?$ & & & $?$ & $?$ & $?$ \\
\hline Resch 2005 & $?$ & $?$ & & $?$ & & $?$ & $?$ & $?$ & $?$ \\
\hline Rosen 2001 & + & $?$ & & $?$ & $?$ & $?$ & $?$ & + & + \\
\hline Saygi 2010 & & & & $?$ & + & $?$ & $?$ & $?$ & + \\
\hline Yip 2002 & & & & $?$ & $?$ & $?$ & $?$ & $?$ & + \\
\hline
\end{tabular}




\section{Allocation}

All five trials (Anderson 1993; Ghnaimat 2005; Needoff 1993; Saygi 2010; Yip 2002) using quasi-randomised methods for treatment allocation were judged to be at high risk of selection bias. Risk of bias relating to random sequence generation was considered low for the three trials (Draper 1997; Finsen 1992; Rosen 2001) that provided a description of the method used. However, an imbalance between the two groups of Draper 1997 in the numbers of participants (182 versus 121), with the possibility that some participants with low mental function scores were not given traction by nursing staff, points to a probable lack of safeguards to allocation concealment in this trial. Given the lack of information, risk of selection bias relating to allocation concealment was judged 'unclear' for Finsen 1992 and Rosen 2001. Allocation concealment seemed very likely in Jerre 2000, where randomisation was by sealed opaque envelopes and involved the use of a telephone line. The use of closed envelopes in Resch 1998 and Resch 2005 was considered insufficient to safeguard allocation concealment. There was, however, an unexplained imbalance in the number of participants in the three groups in Resch 2005: the number in the special foam pillow group (21) was under half that in each of the other two groups (49 and 53).

\section{Blinding}

All 11 trials were considered at high risk of detection bias relating to lack of blinding of subjective outcomes, principally assessment of pain. Objectively-assessed outcomes were generally judged to be less susceptible to bias; and trials were either rated as being at low or unclear risk of blinding-related bias. Only two trials (Anderson 1993; Ghnaimat 2005) included any blinded assessment, which was for ease of fracture reduction in both cases.

\section{Incomplete outcome data}

Six trials (Draper 1997; Finsen 1992; Ghnaimat 2005; Needoff 1993; Resch 1998; Resch 2005) were deemed at high risk of bias relating to incomplete outcome data. In Draper 1997, the large difference in the numbers in each intervention group (121 versus 182) suggests a failure of randomisation methodology. It is also likely that an unknown number of participants allocated traction were transferred to the non-traction group. Post-randomisation exclusions were considered very likely in Finsen 1992. The reasons for high risk of bias judgements were incomplete data and inconsistent percentages in Ghnaimat 2005; incomplete data in Needoff 1993; unresolved discrepancies regarding percentages and numbers at follow-up in Resch 1998; and unresolved discrepancies including numbers randomised in Resch 2005. Both trials (Jerre 2000; Saygi 2010) considered at low risk of attrition bias had no post-randomisation exclusions and gave a clear description of participant flow. There were no short-term losses in either trial; the longer-term losses in Jerre 2000 were few and balanced between the two groups.

\section{Selective reporting}

Trial protocols were unavailable for all trials. Four trials (Anderson 1993; Finsen 1992; Ghnaimat 2005; Needoff 1993) were considered at high risk of bias from selective reporting for reasons given in the Characteristics of included studies. The other seven trials were judged to be at 'unclear' risk of reporting bias.

\section{Other potential sources of bias}

Risk of bias relating to major imbalances in baseline characteristics was judged as low in two trials (Ghnaimat 2005; Rosen 2001), unclear in eight trials but high in Draper 1997. The suggestion, put forward by the trial investigators, that trial participants with low mental function scores assigned traction were not generally given traction by the nursing staff involved indicates fundamental problems with the performance of Draper 1997. Although compensatory analyses were carried out by Draper 1997 in an attempt to counteract the difference in mental function scores of the two groups, the highly statistically significant imbalance in the scores (reported to be $\mathrm{P}<0.001)$ and the numbers who scored zero $(2$ participants of the traction group versus 37 of the no traction group) point to more fundamental problems which probably cannot be totally remedied by post-hoc analyses. Draper estimated that approximately 17 people assigned traction were not given traction, but the lack of a definite number also indicates some slackness in the conduct of this trial. Regrettably, data for this trial are no longer available (personal communication).

The six trials (Anderson 1993; Jerre 2000; Needoff 1993; Rosen 2001; Saygi 2010; Yip 2002) deemed at low risk of performance bias showed generally comparable timing to surgery and use of measures to standardise other treatment such as pre-operative analgesia. The other five trials were judged at 'unclear' risk of performance bias.

\section{Effects of interventions}

Given the above mentioned problems with adherence to trial allocation in Draper 1997, this trial could not be analysed on an intention-to-treat basis. While Draper 1997 attempted to remedy this by using statistical methods to exclude an alternative hypothesis that the trial results reflected the difference in mental function scores, doubts remain about the validity of the results of this study. The various data provided in the study reports for time intervals, such as time between trauma and surgery, hospital admission and 
surgery, and treatment (traction) and surgery, showed no apparent difference between the treatment groups in individual studies. The time to surgery was around 24 hours in most trial participants, which reflects current trends. From an inspection of a graph in Ghnaimat 2005, we estimate that the mean time to surgery was between two and three days in this trial. The mean time to surgery was 53 hours (2.2 days) in Saygi 2010 and 4.7 days in Yip 2002.

\section{Traction versus no traction}

Ten studies (Anderson 1993; Draper 1997; Finsen 1992; Ghnaimat 2005; Jerre 2000; Needoff 1993; Resch 2005; Rosen 2001; Saygi 2010; Yip 2002) compared the application of skin traction with no traction. Finsen 1992 also compared skeletal traction with no traction, as well as comparing skin with skeletal traction. The results from the 21 trial participants allocated to a special foam pillow in Resch 2005 have not been included. This reflects our concerns about the imbalance in the numbers in this group compared with the other two groups of this trial, and that the non-traction intervention is importantly different from the usual control group intervention that, where described, involved the use of an ordinary pillow. Saygi 2010 had two control groups, one involving skin traction device without the use of weights and a pillow beneath the injured limb and the other where a only a pillow was placed beneath the injured limb. Only the results from the pillow only group are presented for this comparison. The data for the two control groups of this trial are presented separately. Data were mostly unavailable for longer-term outcomes such as avascular necrosis (for intracapsular fractures), either because these were not recorded or not reported by these studies.

\section{Pain and analgesia}

Various outcome measures were used by the different trials for assessing pain and pain relief. Nine studies (Anderson 1993; Draper 1997; Ghnaimat 2005; Jerre 2000; Needoff 1993; Resch 2005; Rosen 2001; Saygi 2010; Yip 2002) used a visual analogue pain score to measure pain; Draper 1997 distinguished between the pain patients felt at rest and that felt when moving in bed. Anderson 1993, Ghnaimat 2005, Jerre 2000, Needoff 1993 and Saygi 2010 found no significant difference between the two groups in pain scores. Resch 2005, Rosen 2001 and Saygi 2010 found no significant difference between the two groups in pain (0 to 10 VAS) soon after immobilisation (mean difference (MD) 0.11 , 95\% CI -0.27 to 0.50 ; see Analysis 1.1). Similar numbers of trial participants in the two groups of Resch 2005 found the process of immobilisation uncomfortable (12/49 versus 13/53; risk ratio (RR) 1.00; $95 \%$ confidence interval (CI) 0.50 to 1.97 ; analysis not shown). While Rosen 2001 found no significant difference in the mean reduction in pain scores at 15 minutes after the application of traction or resting the leg on a pillow (1.24 versus 1.44; reported $\mathrm{P}=0.60)$, the mean reduction in pain score from that before either traction or control to that assessed the next morning was reported as being significantly less in those allocated traction (1.76 versus 2.82; reported $P=0.04$ ). Conversely, Draper 1997 reported a statistically significant difference in the scores for rest pain in the first day after injury in favour of the traction group. However, the clinical significance of the difference in the rest pain scores was not stated by Draper 1997 and no difference between the two groups was noted in the much higher pain on movement scores. More traction group participants considered their intervention (traction or pillow rest) painful in Rosen 2001 (27/50 versus 17/50; RR 1.59; 95\% CI 1.00 to 2.52; analysis not shown). Saygi 2010 found no significant difference between the groups at 12 hours post surgery (MD $0.24 ; 95 \%$ CI -0.13 to 0.61 ; see Analysis 1.1). Pain scores were collected five times a day until surgery in Yip 2002. Scores for the evening of admission and the first pain score on the next day were stated to be statistically significantly increased (P value $<0.001$ ) for the no traction group. However, the clinical significance of these differences in pain scores was not established. There were no statistically significant differences between groups in the mean daily pain scores for the day of admission or for the following two days.

Analgesic use was recorded by all trials but data for presentation in the analyses were only available from four trials (Anderson 1993; Resch 2005; Rosen 2001; Saygi 2010); see Analysis 1.2 and Analysis 1.3. The data for Anderson 1993 were extracted, from a bar chart of pre-operative analgesia given in the first three days of admission, provided in the trial report. The data from Rosen 2001 represent trial participants who requested pain medication between hospital admission and surgery; on average the time to surgery was between 1.2 days (traction group) and 1.3 days (pillow group). Although there was a tendency for more traction group participants to receive analgesics in the first day in Anderson 1993 there was no significant difference between the two groups (54/ 101 versus $71 / 151$; RR $1.14,95 \%$ CI 0.89 to 1.46 ); and there was no difference between the two groups in the proportions of trial participants, still awaiting surgery, who received analgesia in the second day (32/64 versus 44/90; RR 1.02, 95\% CI 0.74 to 1.41). Anderson 1993 concluded that there was "no difference" between the groups in terms of analgesic use. Conversely, Rosen 2001 found that as well as a tendency for more traction group participants to receive analgesics before surgery ( $45 / 50$ versus $39 /$ 50; RR $1.15,95 \%$ CI 0.97 to 1.37 ), significantly more traction group participants received greater than the median value of the medication dosages adjusted for a 24 hour period (32/50 versus 18/50; RR 1.78, 95\% CI 1.16 to 2.72). Resch 2005 found no significant difference between the groups in the analgesic use on the ward (MD in number of doses $-0.20,95 \% \mathrm{CI}-1.16$ to 0.76 ; see Analysis 1.3). While Saygi 2010 found no significant difference in the number of analgesic injections per day between the groups, the results tended to favour the no-traction group (MD 0.12, 95\% CI 0.0 to 0.4; see Analysis 1.3). Draper 1997 reported that there was no significant difference in the number of doses of analgesics 
received by participants of the two groups and Jerre 2000 stated there was no significant difference in the analgesic requirements between the two groups. Finsen 1992, while emphasising their reservations about analgesic use as a measure of need for pain relief, noted the skeletal traction group received more pain medication than the no traction group; there was no apparent difference between the skin traction and no traction group. Needoff 1993, where all patients received analgesia on admission, reported a statistically significant increase in the consumption of analgesics in the traction group compared with that for the no traction group in the first day, but not in the second day. Both Ghnaimat 2005 and Yip 2002 provided insufficient data for us to confirm the reported lack of statistically significant differences in analgesia requirements between the two groups.

\section{Pressure sores}

Seven studies (Anderson 1993; Draper 1997; Ghnaimat 2005; Jerre 2000; Needoff 1993; Yip 2002; Saygi 2010) reported pressure sores. Anderson 1993 reported that all trial participants had grade 1 pressure sores ("simple erythema") during their stay in hospital, but found no significant difference between groups in the numbers of people with grade 2 and above pressure sores (separate data for groups not given in report). Twenty-two separate pressure sites on each person were inspected daily until the seventh postoperative day in Draper 1997. No difference was found in the "global" scores of the two groups, and the only site to show any significant difference, in favour of the traction group, was the heel of the contralateral leg to the injured leg $(P=0.016)$. However, the clinical significance of this finding was questioned by Draper 1997, who indicated that there were no cases of skin ulceration or skin breakage at this site. There were no deep sores in Draper 1997 and few (21) observations of sites with ulceration; Draper considered that the regular examination of pressure sites might have helped reduce the risk of pressure sores. Jerre 2000 noted that, prior to surgery, five participants of the traction group developed grade 1 pressure or wound sores as opposed to none in the group with no traction (see Analysis 1.4: RR 11.0, 95\% CI 0.62 to 194.63). Ghnaimat 2005 reported that 14 patients developed a grade 2 pressure sore while in hospital. They reported, without providing data, that there was no significant difference between the two groups in the number of pressure sores. Needoff 1993 indicated that there was no difference in pressure sores between the two groups (personal communication). Saygi 2010 reported that two patients in the traction group developed pressure sores postoperatively. No trial participant had a pressure sore in Yip 2002 (personal communication).

\section{Fracture reduction}

Five studies considered fracture reduction. Both Anderson 1993 and Ghnaimat 2005 found no significant difference in ease of fracture reduction as assessed by the operating surgeons who were blinded to treatment (see Analysis 1.5 Difficulty in fracture reduction: $15 / 81$ versus $19 / 102$; RR 0.92 , $95 \%$ CI 0.51 to 1.67 ). Finsen 1992 found a significantly reduced reduction time for those fractures treated without traction. However Finsen 1992 found no significant difference between the two groups in the overall operating time. Jerre 2000 considered the quality of fracture reduction and found no significant difference in the quality of fracture reduction related to the use of traction (see Analysis 1.6 Poor quality fracture reduction: $2 / 60$ versus 3/60; RR $0.67,95 \%$ CI 0.12 to 3.85 ).

\section{Complications}

Later complications, all minor, in Jerre 2000 included pressure sores and urinary tract infections but no thromboses or wound infections; post-operative complications occurred in 10 participants of traction group and 13 of those without traction (see Analysis 1.4: RR 0.77, 95\% CI 0.37 to 1.62). At three to four days followup, four traction group participants of Resch 2005 had complications (two of erythema, one of oedema, and one of paraesthesia) but none of the control group (see Analysis 1.4: RR 9.72, 95\% CI 0.54 to 176.00). Saygi 2010 reported that three patients in the traction group had complications; two had pressure sores and one had neuropraxia.

\section{Adverse effects of treatment}

Complications directly related to traction were referred to in four studies. Anderson 1993 and Ghnaimat 2005 noted that no trial participant suffered direct skin damage as a result of the application of traction and Yip 2002 stated that there were no complications related to either the use or non-use of traction in their trial. Conversely, Rosen 2001 reported that one person in the traction group suffered from transient sensory changes in the leg and a further two people developed superficial skin blisters. One patient in the traction group developed neuropraxia in Saygi 2010; however, it is not clear that this was an adverse effect of traction.

\section{Fracture healing complications}

Fracture healing complications were not well documented. Jerre 2000 was the only study to report on fracture healing complications for 110 out of 120 trial participants. Fracture healing failures at four months are presented, with separate data for intracapsular and extracapsular fractures, in Analysis 1.8: 14/54 versus 9/56; RR 1.61, 95\% CI 0.76 to 3.41. For intracapsular fractures, fracture healing was deemed to have failed in 11 out of 26 intracapsular fractures allocated to traction and nine out of 29 allocated to no traction. For the trochanteric fractures, fracture healing was reported as failing in three out of 28 cases allocated to traction and none out of 27 cases allocated to no traction. None of these differences were statistically significant. Jerre 2000 also reported on fracture compression at one week after surgery and stated there 
was no significant difference between groups. Needoff 1993 had intended to assess the incidence of avascular necrosis at one year in a subgroup of minimally displaced femoral neck fractures but found there were insufficient numbers of these to continue.

\section{Mortality}

Two studies (Finsen 1992; Jerre 2000) reported mortality. Finsen 1992 reported two pre-operative deaths in the no traction group and Jerre 2000 reported that seven deaths had occurred by fourmonths follow-up.

\section{Other outcomes}

All four studies (Finsen 1992; Needoff 1993; Resch 2005; Yip 2002) reporting overall operating time found there was no significant difference between the two groups. Pooled data from two studies (Resch 2005; Yip 2002) are shown in Analysis 1.9 (MD 1.28 minutes, $95 \%$ CI -4.82 to 7.39 minutes). Yip 2002 also found no significant difference between the two groups in mean intra-operative blood loss (see Analysis 1.10).

Finsen 1992 found an increased blood loss during surgery in the skeletal traction group (significant for trochanteric fractures) but not in the skin traction group when compared with the no traction group. Anderson 1993 found no significant difference in the length of hospital stay (see Analysis 1.11). Similarly, Ghnaimat 2005 reported no significant difference in the length of hospital stay (19.1 versus 18.4 days).

\section{Skin traction versus 'placebo' traction (without weights) or no traction}

As described above, Saygi 2010 had two control groups, one involving skin traction device without the use of weights and a pillow beneath the injured limb, and the other where only a pillow was placed beneath the injured limb. For completeness, but with no prior expression to present such a comparison, the results for the traction group were compared with each of the two control groups and are presented for pain soon after immobilisation (see Analysis 2.1), pain at 12 hours (see Analysis 2.2) and analgesic use (see Analysis 2.3). Although the results favour the 'placebo' traction group more than the pillow only group, there were no significant differences between the two subgroups for any of the three analyses.

\section{Skin traction versus skeletal traction}

Two studies (Finsen 1992; Resch 1998) compared skin versus skeletal traction. Neither study recorded longer-term outcomes.

\section{Pain and analgesia}

Resch 1998 found no difference between the two groups in pain soon after traction as measured on a visual analogue scale (see Analysis 3.1). Resch 1998 stated that significantly more people (reported $\mathrm{P}=0.03$ ) found the application of skeletal traction painful ( $50 \%$ of skeletal compared with $20 \%$ of skin traction group participants) but data for presentation in the analyses were not available (see 'Notes' for Resch 1998 in Characteristics of included studies). As stated above, Finsen 1992 noted an increase in the use of analgesia medications in the skeletal traction group. Although Resch 1998 reported a small but significant reduction in the mean number of analgesic medications for those treated with skeletal traction (see Analysis 3.2: mean difference 0.80, 95\% CI 0.13 to 1.47), they concluded that this difference had no clinical significance.

\section{Fracture reduction}

Finsen 1992 found no difference in the time taken to reduce the fracture.

\section{Complications}

Resch 1998 stated that no complications were seen in either traction method.

\section{Other outcomes}

Finsen 1992 found no difference in length of surgery. Resch 1998 reported no significant difference in the length of operation (see Analysis 3.3: mean difference -10.0 minutes, $95 \%$ CI -23.65 to 3.65 minutes).

As noted above, Finsen 1992 reported an increased blood loss for skeletal traction which was significant for trial participants with trochanteric fractures.

Finsen 1992 observed that traction involved additional hospital resources, particularly skeletal traction which required use of an operating theatre. Resch 1998 reported no significant difference in the time spent in the emergency department where the traction was applied.

\section{DISCUSSION}

The continuing relevance of the review question is shown by the continuing variation in practice and the availability of new trials. Traction prior to surgery for an acute hip fracture used to be routine and in some hospitals remains standard practice. For example, a survey of 78 hospitals in Sweden (Billsten 1996) showed that a quarter of these routinely applied skin traction to all hip fractures. Another survey (Brink 2005) found pre-operative traction was standard practice in $20 \%$ of trauma departments in the 
Netherlands, mainly for an assumed reduction in pain. In a study of hip fracture and pressure sores, Lindholm 2008 reported that traction had been applied in $6 \%$ of patients from centres from four north Europeon countries and $74 \%$ of patients from three south European countries. Notably, guidelines based on evidence from the previous versions of this review have advised against the routine use of traction (NZGG 2003; SIGN 2009).

\section{Summary of main results}

This review summarizes the evidence from 11 randomised or quasi-randomised controlled trials (1654 participants) examining the use of pre-operative traction in adults with hip fracture. Ten trials compared traction versus no traction (injured limb placed on an ordinary pillow) and two trials, including one of the preceding 10, compared skin traction versus skeletal traction. Only limited pooling of results was possible due to the different outcome measures used or incomplete data. There were very limited data available for long term outcomes.

For the traction versus no traction comparison, none of the available data showed significant differences between the groups in pain reduction after the application of traction as measured by visual analogue scores or analgesic use. Although the data were just from three trials, it is noteworthy that the pooled $95 \%$ confidence interval $(-0.27$ to 0.50$)$ in Analysis 1.1 did not include minimal clinically important differences. The few pressure sores data available for graphical presentation also showed no statistically significant difference between the two groups; this was claimed also by other trials reporting this outcome. A similar result of no statistically significant difference was generally found for the available data, often from single trials, for secondary outcomes, namely ease of fracture reduction, fracture fixation complications, complications, operative time and blood loss, length of hospital stay. For most of these outcomes, the results favoured no traction more than the traction group. All three complications reported as directly linked to traction use were minor and resolved without sequelae. Overall, despite significant limitations in the methodology of most trials and the limited availability of data for pooling, the evidence from these 10 trials consistently failed to show any benefit from preoperative traction during the peri-operative period. All of the trials included in this review so far have concluded that since traction does not significantly reduce the degree of pain the patient experiences pre-operatively or, where recorded, aid reduction of the fracture, its routine use may be superfluous.

Limited data from the two trials comparing skin with skeletal traction showed no important differences between these two methods in pain, analgesic requirement, ease of fracture reduction or operative time. However, the initial application of skeletal traction was noted as being more painful and more costly.

\section{Overall completeness and applicability of evidence}

The included trials had varied and incomplete ascertainment of outcome, and only very limited pooling of results was possible. It is clearly unsatisfactory but unavoidable to be reporting findings from trials that cannot be included in a meta-analyses or otherwise examined. The consistency of pain results from the available data for analysis and reported lack of differences between traction and no traction in the other trials not providing data adds credibility to this finding. This has been supported by the addition of comparable data from yet another trial in this update. As described below, the data for the other primary outcome of pressure sores are even more unsatisfactory and incomplete.

Hypothetically, people treated with traction are more likely to suffer from pressure sores since the use of traction inhibits the proper turning of the patient. This is not confirmed in this review but various deficiencies in the trials and the available data prevent conclusions being drawn. One major issue is the monitoring and measurement of pressure sores. The monitoring of complications including pre-operative pressure sores was poorly reported in most trials, and separate group data for the more serious grades of pressure sore were not available for four trials reporting these. By far the most assiduous collection of pressure sore data was done by Draper 1997, who reported that of 46,958 observations of 22 pressure sites in each patient on a daily basis over seven days, there were 21 instances of skin ulceration. But again data split by treatment group were not available for this albeit flawed trial.

The majority of participants were over 80 years of age and female; and thus representative of the general population with these fractures in many countries. However, five trials excluded patients with dementia or cognitive impairment. The applicability of the review findings is enhanced by the availability of data from several countries. It is notable though that while the time to surgery was around 24 hours in most trial participants, which reflects current trends and aspirations in several countries, time to surgery was greater in three more recently included trials based in Hong Kong (mean 4.7 days), Jordan (2 to 3 days) and Turkey (mean 2.2 days). The median time between arrival and surgery was 90 hours in centres in three south European countries in Lindholm 2008. It is not clear from the trial results whether prolonged traction may confer additional benefit or be associated with increased complications. However, the extended use of traction in Yip 2002 did not appear to be of advantage: the graphs of pain scores and analgesic requirement presented in the trial report showed a decline for both groups in pain and analgesic consumption after peaking in the day following admission.

There was no evidence to examine whether the arguments for and against traction apply equally for both intracapsular and extracapsular fractures; or for other subgroups of hip fracture patients, such as those with displaced intracapsular fractures or subtrochanteric fractures. Though two trials (Finsen 1992; Jerre 2000) presented separate data for extracapsular and intracapsular frac- 
tures, the numbers of patients within these groups were too small to be able to draw conclusions. Another trial (Resch 2005) stated without providing evidence that "fracture type did not affect outcome". As noted by SIGN 2009, "The small numbers and limitations of the studies cannot exclude possible advantages of traction for specific fracture types".

\section{Quality of the evidence}

The quality of the trials included in this review continues to disappoint. The trial (Saygi 2010) newly included in this update was quasi-randomised, as were two of the three trials added in the more recent updates. Inspection of Figure 2, which summarises the judgements about each risk of bias item across all included studies, shows that 10 out of the 11 included trials were at high or unclear risk of selection bias. Detection bias of subjective out- comes (primarily pain) is arguably inevitable for these trials. An attempt at 'placebo' traction in Saygi 2010, which found statistically significant results in favour of the placebo group, prompts the question of whether the non-use of weights can be considered 'placebo' traction. We do not think it does. Another serious weakness and source of bias in these trials results from incomplete outcome data; a clear description of participant flow was available in only two trials. Newly considered in this update is selective reporting bias. Absence of trial protocols meant that we were unable to judge any trial as being at 'low' risk of bias for this important item. However, four trials were considered at high risk. In the results we drew attention to the problems surrounding Draper 1997, including a major imbalance in baseline characteristics. The problems of Draper 1997 show the immense care that is required in conducting trials, including having robust methods of allocation concealment, and guarding against breaches in the trial protocol.

\section{Figure 2. Risk of bias graph: review authors' judgements about each risk of bias item presented as}

percentages across all included studies.

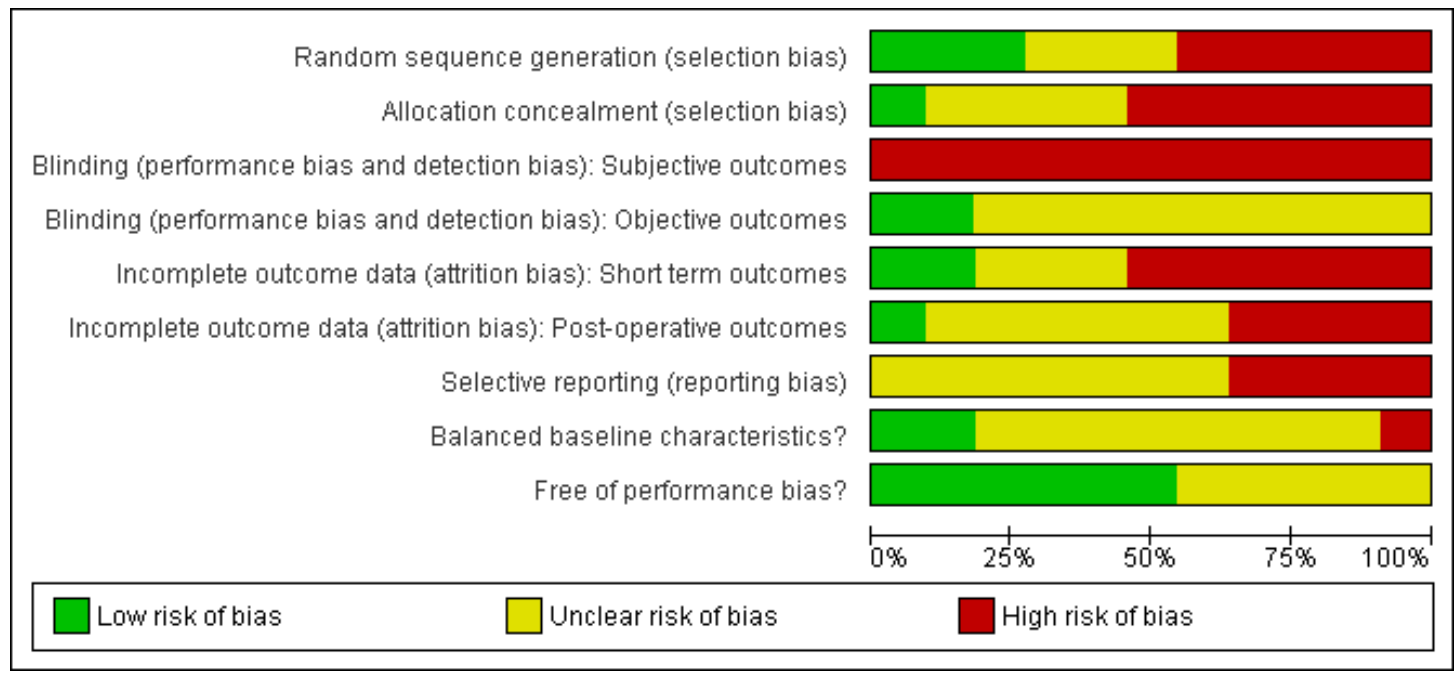

\section{Potential biases in the review process}

While our search was comprehensive it is likely that we have failed to identify some randomised trials, particularly those reported only in abstracts or in non-English language publications. The latter possibility is reinforced by geographical distribution of the included trials. However, we are almost certain that substantial randomised controlled trials that could provide the definitive evidence needed in this area would be published and identifiable by our search. Systematic processes were undertaken throughout the review and a cautious approach taken in interpreting the evidence. The planned summary of findings tables were not compiled given the limited and variably reported results.

\section{AUTHORS, CONCLUSIONS}




\section{Implications for practice}

From the limited evidence available, there is no proven benefit for the routine use of traction (either skin or skeletal) prior to surgery for a hip fracture. However, the limited numbers of patients involved and the flawed methodology of the studies means that potential advantages for traction, in particular for specific fracture types, cannot be refuted. The potential for complications, such as pre-operative pressure sores, arising from the use of traction should also be considered.

The continuing and increasing lack of evidence over successive updates to support pre-operative traction is noteworthy. We suggest that this should give considerable pause for thought where pre-operative traction is being considered, with the onus being on clinicians to provide the evidence for its use.

\section{Implications for research}

The trials so far conducted have not shown any benefit from the use of traction prior to surgery for hip fracture but were not sufficient to confirm this, nor additional complications due to traction use. We recommend that clinicians continuing to use pre-opera- tive traction should do so in the context of a randomised controlled trial. In any future trials planned, the aim should be to minimise bias particularly by allocation concealment and blind assessment of appropriate outcome measures, including patient satisfaction and fracture healing complications, defined in the study protocol. Confounding should be minimised by ensuring that, other than the traction option, care programmes are the same for all participants. Full reporting of trial methods and outcomes, including the provision of standard deviations where appropriate, is also essential. Given the potential of trials to influence both clinical practice and future research, we recommend that original data should be retained to enable future scrutiny.

\section{ACKNOWLEDGEMENTS}

We thank Dr Joanne Elliott for updating the search strategies and performing the database searches for this update. Thanks also to Mrs Lindsey Elstub and Prof Rajan Madhok for their helpful comments at editorial review.

\section{R E F E R E N C E S}

\section{References to studies included in this review}

Anderson 1993 \{published data only\}

Anderson GH, Harper WM, Badham J, Goodrich N, Gregg PJ. The effect of pre-operative skin traction on pain and morbidity following fracture of the proximal femur - a randomised prospective trial [abstract]. Journal of Bone and Joint Surgery - British Volume 1993;75 Suppl 1:42.

* Anderson GH, Harper WM, Connolly CD, Badham

J, Goodrich N, Gregg PJ. Preoperative skin traction for fracture of the proximal femur. Journal of Bone and Joint Surgery - British Volume 1993;75(5):794-6. [MEDLINE: 1993388677]

\section{Draper 1997 \{published and unpublished data\}}

Draper P. personal communication July 202000.

Draper P. A clinical trial of Hamilton-Russell traction on

a) incidence of pressure sores, and b) pre-operative pain, in patients with fractured neck of femur. In: The National Research Register, Issue 3, 2000. Oxford: Update Software.. * Draper P, Scott F. An evaluation of Hamilton-Russell traction in the pre-operative management of patients with hip fracture. Clinical Effectiveness in Nursing 1997;1(4): $179-88$.

Draper P, Scott F. Report of a project to evaluate the use of Hamilton Russell traction in the pre-operative management of patients with hip fracture. Hull (UK): The School of
Health, The University of Hull; 1997.

Draper P, Scott F. Using traction... Hamilton-Russell traction. Nursing Times 1998;94(12):31-2.

Scott F, Butler M. Easing the pressure for hip fracture patients. Nursing Times 1995;91(29):30-1.

Finsen 1992 \{published data only\}

* Finsen V, Borset M, Buvik GE, Hauke I. Preoperative traction in patients with hip fractures. Injury 1992;23(4): 242-4. [MEDLINE: 1992316657]

Finsen V, Borset M, Buvik GE, Hauke I. Preoperative traction in patients with hip fractures [abstract]. Acta Orthopaedica Scandinavica. Supplementum 1991;243:21-2.

Ghnaimat 2005 \{published data only\}

Ghnaimat M, Aldweri M, Hijazi A, Shawabkeh J, Obeid I, Magableh H, et al.Preoperative skin traction for fractures of the proximal femur. Journal of the Bahrain Medical Society 2005;17(4):240-2.

Jerre 2000 \{published and unpublished data\}

Jerre R, Doshe A, Karlsson J. Preoperative treatment in patients with hip fractures [abstract]. Acta Orthopaedica Scandinavica. Supplementum 1999;284:40.

* Jerre R, Doshe A, Karlsson J. Preoperative treatment in patients with hip fractures is not useful. Clinical Orthopaedics and Related Research 2000;(378):169-73. Koval KJ. Preoperative skin traction was not useful for hip fractures. Journal of Bone and Joint Surgery - American Volume 2001;83(2):303. 
Needoff 1993 \{published and unpublished data\}

Needoff M, Radford P, Langstaff R. Preoperative traction for femoral neck fractures [abstract]. Injury 1993;24(4):280-1.

* Needoff M, Radford P, Langstaff R. Preoperative traction for hip fractures in the elderly: a clinical trial. Injury 1993; 24(5):317-8. [MEDLINE: 1993352147]

Resch 1998 \{published and unpublished data\}

Resch S. personal communication March 82006. Resch S, Thorngren KG. Preoperative skin vs. skeletal traction in patients with hip fractures - the effect on pain and on patient flow characteristics [abstract]. Acta Orthopaedica Scandinavica. Supplementum 1996;270:34-5.

* Resch S, Thorngren K-G. Preoperative traction for hip fracture: A randomized comparison between skin and skeletal traction in 78 patients. Acta Orthopaedica Scandinavica 1998;69(3):277-9. [MEDLINE: 1998366962]

Resch 2005 \{published and unpublished data\}

Resch S. personal communication March 82006.

* Resch S, Bjarnetoft B, Thorngren K-G. Preoperative skin traction or pillow nursing in hip fractures: a prospective, randomized study in 123 patients. Disability and Rehabilitation 2005;27(18-19):1191-5.

Rosen 2001 \{published data only\}

Barnes P. Preoperative pillow placement under the injured extremity had better analgesic effects than skin traction for hip fracture. Evidence-Based Nursing 2002;5(1):24. Chen FS, Rosen JE, Hiebert R, Koval KJ, Zuckerman JD. The efficacy of preoperative skin traction after hip fractures: a prospective randomized study [abstract]. 66th Annual Meeting of the American Academy of Orthopaedic Surgeons; 1999 Feb 4-8: Anaheim (CA). 1999:http: //www.aaos.org/wordhtml/anmeet99/poster/139.html (accessed 02/03/01).

* Rosen JE, Chen FS, Hiebert R, Koval KJ. Efficacy of preoperative skin traction in hip fracture patients: A prospective, randomized study. Journal of Orthopaedic Trauma 2001;15(2):81-5.

Saygi 2010 \{published data only\}

Saygi B, Ozkan K, Eceviz E, Tetik C, Sen C. Skin traction and placebo effect in the preoperative pain control of patients with collum and intertrochanteric femur fractures. Bulletin of the NYU Hospital for Joint Diseases 2010;68(1): $15-7$.

Yip 2002 \{published data only\} Yip DK, Chan CF, Chiu PK, Wong JW, Kong JK. Why are we still using pre-operative skin traction for hip fractures?. International Orthopaedics 2002;26(6):361-4.

\section{Additional references}

\section{Altman 2003}

Altman DG, Bland JM. Interaction revisited: the difference between two estimates. BMJ 2003;326(7382):219.

Bergstrom 2009

Bergstrom U, Jonsson H, Gustafson Y, Pettersson U, Stenlund H, Svenssoson O. The hip fracture incidence curve is shifting to the right. Acta Orthopaedica 2009;80(5): $520-524$.

\section{Billsten 1996}

Billsten M, Besjakov J, Hyddmark U, Johnell O, Sernbo I. Enquiry in Sweden on the use of traction preoperatively in patients with hip fracture and a radiological study on the effect of the traction on ten displaced cervical hip fractures [abstract]. Acta Orthopaedica Scandinavica. Supplementum 1996;270:35.

Bjorgul 2007

Bjorgul K, Reikeras O. Incidence of hip fracture in southeastern Norway: a study of 1730 cervical and trochanteric fractures. International Orthopaedics 2007;31 (5):665-669.

\section{Brink 2005}

Brink AC, Boonstra O, van Der Wal BCH, Ultee JM, Schipper IB. Is preoperative traction for proximal femoral fractures beneficial to the patient or a comfort to the doctor? . European Journal of Trauma 2005;31(1):39-43.

\section{Haentjens 2005}

Haentjens P, Lamraski G, Boonen S. Costs and consequences of hip fracture occurrence in old age: an economic perspective. Disability and Rehabilitation 2005;27(18-19): 1129-1141.

\section{Higgins 2003}

Higgins JPT, Thompson SG, Deeks JJ, Altman DG. Measuring inconsistency in meta-analyses. BMJ 2003;327: $557-60$.

\section{Higgins 2005}

Higgins JPT, Green S, editors. Highly sensitive search strategies for identifying reports of randomized controlled trials in MEDLINE. Cochrane Handbook for Systematic Reviews of Interventions 4.2.5 [updated May 2005]; Appendix 5b. In: The Cochrane Library, Issue 3, 2005. Chichester, UK: John Wiley \& Sons, Ltd.

\section{Higgins 2008a}

Higgins JPT, Altman DG (editors). Chapter 8: Assessing risk of bias in included studies Table 8.5a. Chapter 8: Assessing risk of bias in included studies. In: Higgins JPT, Green S (editors). Cochrane Handbook for Systematic Reviews of Interventions Version 5.0.1 (updated September 2008). The Cochrane Collaboration, 2008. Available from www.cochrane-handbook.org.

\section{Higgins 2008b}

Higgins JPT, Green S (editors). Cochrane Handbook for Systematic Reviews of Interventions Version 5.0.1 [updated September 2008]. The Cochrane Collaboration, 2008. Available from www.cochrane-handbook.org.

\section{Kannus 1996}

Kannus P, Parkkari J, Sievänen H, Heinonen A, Vuori I, Järvinen M. Epidemiology of hip fractures. Bone 1996;18 (Suppl 1):57S-63S

\section{Kemler 2006}

Kemler MA, de Vries M, van der Tol A. Duration of preoperative traction associated with sciatic neuropathy 
after hip fracture surgery. Clinical Orthopaedics and Related Research 2006;445:230-32.

\section{Koh 2001}

Koh LK, Saw SM, Lee JJ, Leong KH, Lee J. Hip fracture incidence rates in Singapore 1991-1998. Osteoporosis International 2001;12(4):311-318.

\section{Lindholm 2008}

Lindholm C, Sterner E, Romanelli M, Pina E, Torra y Bou J, Hietanen $\mathrm{H}$, et al.Hip fracture and pressure ulcers - the Pan-European Pressure Ulcer Study - intrinsic and extrinsic risk factors. International Wound Journal 2008;5 (2):312-28.

\section{Lyons 1997}

Lyons AR. Clinical outcomes and treatment of hip fractures. The American journal of medicine 1997;18(103(2A)):51-64.

\section{Maruenda 1997}

Maruenda JI, Barrios C, Gomar-Sancho F. Intracapsular hip pressure after femoral neck fracture. Clinical Orthopaedics and Related Research 1997;(340):172-80.

\section{Moran 2010}

Gunasekera N, Boulton C, Morris C, Moran C. Hip fracture audit: the Nottingham experience. Osteoporosis international 2010;21 (Suppl 4):S647-S653.

\section{NZGG 2003}

New Zealand Guidelines Group. Acute management and immediate rehabilitation after hip fracture amongst people aged 65 years and over. New Zealand Guidelines Group. Best practice evidence-based guideline. www.nzgg.org.nz (accessed 25/08/2011) 2003:a-26

\section{Shabat 2002}

Shabat S, Gepstein R, Mann G, Kish B, Fredman B, Nyska M. Deep skin slough following skin traction for hip fractures. Journal of Tissue Viability 2002;12(3):108-12.

\section{SIGN 2009}

SIGN. Management of hip fracture in older people. A national clinical guideline. Guideline No. 111. Scottish Intercollegiate Guidelines Network www.sign.ac.uk/ guidelines/fulltext/111/index.html (accessed 25/08/2011) 2009: Cover-50.

\section{Stromqvist 1988}

Stromqvist B, Nilsson LT, Egund N, Thorngren K-G,

Wingstrand $\mathrm{H}$. Intracapsular pressures in undisplaced fractures of the femoral neck. Journal of Bone and Joint Surgery. British Volume 1988;70(2):192-4.

\section{Svalastoga 1989}

Svalastoga E, Kiaer T, Jensen PE. The effect of intracapsular pressure and extension of the hip on oxygenation of the juvenile femoral epiphysis. Journal of Bone and Joint Surgery. British Volume 1989;71(2):222-6.

\section{References to other published versions of this review}

\section{Parker 1997}

Parker MJ, Handoll HHG. Pre-operative traction for fractures of the proximal femur. Cochrane Database of Systematic Reviews 1997, Issue 3.

\section{Parker 2000}

Parker MJ, Handoll HHG. Pre-operative traction for fractures of the proximal femur. Cochrane Database of Systematic Reviews 2000, Issue 2.

\section{Parker 2001a}

Parker M, Handoll HHG. Pre-operative traction for fractures of the proximal femur. Cochrane Database of Systematic Reviews 2001, Issue 1.

\section{Parker 2001b}

Parker MJ, Handoll HHG. Pre-operative traction for fractures of the proximal femur. Cochrane Database of Systematic Reviews 2001, Issue 3. [DOI: 10.1002/ 14651858.]

Parker 2003

Parker MJ, Handoll HHG. Pre-operative traction for fractures of the proximal femur. Cochrane Database of Systematic Reviews 2003, Issue 3. [DOI: 10.1002/ 14651858.CD000168]

\section{Parker 2004}

Parker MJ, Handoll HHG. Pre-operative traction for fractures of the proximal femur. Cochrane Database of Systematic Reviews 2004, Issue 4.

\section{Parker 2006}

Parker MJ, Handoll HHG. Pre-operative traction for fractures of the proximal femur in adults. Cochrane Database of Systematic Reviews 2006, Issue 3. [DOI: 10.1002/ 14651858.CD000168.pub2]

* Indicates the major publication for the study 


\section{CHARACTERISTICS OF STUDIES}

\section{Characteristics of included studies [ordered by study ID]}

\section{Anderson 1993}

\begin{tabular}{ll}
\hline Methods & Randomised by last digit of patient's registration number. \\
\hline Participants & 252 people with a proximal femoral fracture \\
& Hospital in Leicester, UK \\
& Period of study: November 1991 to July 1993 \\
& Excluded: patients refusing consent, senile patients, and patients with conditions which \\
& contraindicated the use of skin traction as specified in the published article \\
Mean age: 81 years & Females: $77 \%$ \\
Intracapsular fractures: $46 \%$ & Assigned: $101 / 151$ [traction / control] \\
\hline
\end{tabular}

Interventions

Pre-operative skin traction using $2.3 \mathrm{~kg}$ weight of traction applied via Hamilton-Russell traction versus those nursed free in bed (exact method of nursing the injured limb not specified)

\begin{tabular}{ll} 
Outcomes & Length of follow-up: unknown (until discharge) \\
& Daily pain scores (visual analogue score 0 [no pain] to 10 [worst pain]) \\
Analgesic use on day 1, 2 and 3 & $\begin{array}{l}\text { Pressure sores (grades } 1 \text { and 2; reference to Morison 1989. Grade 1 = "simple erythema") } \\
\text { Difficulty in fracture reduction } \\
\text { Length of hospital stay }\end{array}$ \\
\hline Notes & Pain scale direction inferred. \\
\hline
\end{tabular}

Risk of bias

\begin{tabular}{|c|c|c|}
\hline Bias & Authors' judgement & Support for judgement \\
\hline $\begin{array}{l}\text { Random sequence generation (selection } \\
\text { bias) }\end{array}$ & High risk & $\begin{array}{l}\text { "The patients were randomised using the } \\
\text { last digit of their registration number." }\end{array}$ \\
\hline Allocation concealment (selection bias) & High risk & $\begin{array}{l}\text { Quasi-randomised - based on hospital reg- } \\
\text { istration number. }\end{array}$ \\
\hline $\begin{array}{l}\text { Blinding (performance bias and detection } \\
\text { bias) } \\
\text { Subjective outcomes }\end{array}$ & High risk & $\begin{array}{l}\text { No blinding except surgeon unaware of the } \\
\text { preoperative regimen }\end{array}$ \\
\hline $\begin{array}{l}\text { Blinding (performance bias and detection } \\
\text { bias) } \\
\text { Objective outcomes }\end{array}$ & Low risk & $\begin{array}{l}\text { Unlikely to be affected: mortality, duration } \\
\text { of operation, bleeding }\end{array}$ \\
\hline
\end{tabular}




\begin{tabular}{l|l|l}
$\begin{array}{l}\text { Incomplete outcome data (attrition bias) } \\
\text { Short term outcomes }\end{array}$ & Unclear risk & $\begin{array}{l}\text { Active surveillance but poor reporting with } \\
\text { reliance on graphs }\end{array}$ \\
\hline $\begin{array}{l}\text { Incomplete outcome data (attrition bias) } \\
\text { Post-operative outcomes }\end{array}$ & Unclear risk & $\begin{array}{l}\text { No mention of mortality with respect to } \\
\text { hospital length of stay }\end{array}$ \\
\hline Selective reporting (reporting bias) & High risk & $\begin{array}{l}\text { No protocol. Some possible post-hoc deci- } \\
\text { sions, such as presenting fracture reduction } \\
\text { data for one surgeon; and reporting of pres- } \\
\text { sure sore results }\end{array}$ \\
\hline Balanced baseline characteristics? & Unclear risk & $\begin{array}{l}\text { The baseline characteristics appeared bal- } \\
\text { anced ("well matched"). With reference to } \\
\text { the imbalance in patient numbers in the } \\
\text { two groups the authors stated: "The reason } \\
\text { for the difference is unclear and may relate } \\
\text { to the allocation of registration numbers by } \\
\text { the hospital administration." }\end{array}$ \\
\hline
\end{tabular}

\section{Draper 1997}

\begin{tabular}{|c|c|}
\hline Methods & $\begin{array}{l}\text { Randomised using a random numbers table to order colour coded booklets (pink = } \\
\text { traction; blue = no traction) into a pile. The top envelope of the pile was withdrawn } \\
\text { when a patient was admitted into the study. } \\
\text { Possibility of post-randomisation exclusions or transfer of patients from one group to } \\
\text { another (see Notes) }\end{array}$ \\
\hline Participants & $\begin{array}{l}303 \text { people with a proximal femoral fracture } \\
\text { Hospital in Hull, UK } \\
\text { Period of study: not stated } \\
\text { Excluded: patients refusing consent; multiple fractures or injuries; presence of pressure } \\
\text { sores graded } 3 \text { or above at hospital admission; transfer from another hospital; fracture } \\
\text { not considered suitable for surgical treatment; absence, paralysis or severe contraction } \\
\text { of lower limb; presence of skin condition severe enough to prevent application of skin } \\
\text { extension tapes. } \\
\text { Mean age: } 80.5 \text { years } \\
\text { Female: } 84.5 \% \\
\text { Intracapsular fractures : } 48.5 \% \\
\text { Assigned: } 121 / 182 \text { [traction / control] }\end{array}$ \\
\hline
\end{tabular}




\begin{tabular}{ll} 
Interventions & $\begin{array}{l}\text { Pre-operative skin traction using } 2.5 \mathrm{~kg} \text { weight of traction applied via Hamilton-Russell } \\
\text { traction versus those nursed free in bed (injured limb placed on pillow; patient encour- } \\
\text { aged to adopt position of greatest comfort) }\end{array}$ \\
\hline Outcomes & $\begin{array}{l}\text { Length of follow-up: } 7 \text { th post-operative day } \\
\text { Pain scores (visual analogue scale: } 0 \text { [no pain] to } 10 \text { [excruciating pain]): at rest and } \\
\text { during movement in bed, pre-operative only. } \\
\text { Analgesic consumption } \\
\text { Pressure sores }(22 \text { pressure sites inspected and graded. Graded using Torrance } 1983 . \\
\text { Score } 1 \text { = blanching (skin goes white on pressure) erythema, score } 2=\text { non blanching } \\
\text { erythema, score } 3=\text { ulceration) }\end{array}$ \\
\hline
\end{tabular}
the number of participants with low (0) mental test scores ( 2 versus 37). The authors suggested the reason for this might be failure by nursing staff to apply traction to mentally confused participants allocated to the traction group; these were then included in the non-traction group. Because of this potential bias in the different characteristics of the two groups, analysis of co-variance was undertaken by the authors to try to correct for the imbalance

\section{Risk of bias}

\begin{tabular}{|c|c|c|}
\hline Bias & Authors' judgement & Support for judgement \\
\hline $\begin{array}{l}\text { Random sequence generation (selection } \\
\text { bias) }\end{array}$ & Low risk & $\begin{array}{l}\text { "We used a random numbers table. We } \\
\text { had colour coded booklets for data collec- } \\
\text { tion - pink for traction and blue for control } \\
\text { group. We used a random numbers table } \\
\text { to place the book on order. Odd numbers } \\
\text { = pink = traction, even numbers = blue = } \\
\text { no traction - and then as patients were ad- } \\
\text { mitted to the study we allocated the next } \\
\text { book that was on top of the pile." (personal } \\
\text { communication) }\end{array}$ \\
\hline Allocation concealment (selection bias) & High risk & There was no concealment of allocation. \\
\hline $\begin{array}{l}\text { Blinding (performance bias and detection } \\
\text { bias) } \\
\text { Subjective outcomes }\end{array}$ & High risk & No blinding. \\
\hline
\end{tabular}

Blinding (performance bias and detection Unclear risk bias)

No blinding and no safeguards for pressure

Objective outcomes sore measurement.

Incomplete outcome data (attrition bias) High risk Short term outcomes
Large difference in the numbers in each intervention group (121 versus 182) sug- 
Draper 1997 (Continued)

\begin{tabular}{|c|c|c|}
\hline & & $\begin{array}{l}\text { gests a failure of randomisation methodol- } \\
\text { ogy. Difference in mental cognitive scores } \\
\text { also: number of participants with low (0) } \\
\text { mental test scores ( } 2 \text { versus } 37) \text {. It is likely } \\
\text { that an unknown number of participants } \\
\text { allocated traction were transferred to the } \\
\text { non-traction group }\end{array}$ \\
\hline $\begin{array}{l}\text { Incomplete outcome data (attrition bias) } \\
\text { Post-operative outcomes }\end{array}$ & High risk & $\begin{array}{l}\text { As above, but post-operative pressures sore } \\
\text { results not given }\end{array}$ \\
\hline Selective reporting (reporting bias) & Unclear risk & $\begin{array}{l}\text { Protocol was clearly in place but outcome } \\
\text { analysis modified to address imbalance in } \\
\text { mental cognitive score status }\end{array}$ \\
\hline Balanced baseline characteristics? & High risk & $\begin{array}{l}\text { Major imbalance in mental test scores. } \\
\text { Higher [better] scores in traction group (p } \\
<0.001) \text {. Authors speculated that "poss- } \\
\text { ble explanation is that nurses decided not } \\
\text { to apply traction to patients with very low } \\
\text { mental test scores who had been random- } \\
\text { ized to the traction group." "Number of pa- } \\
\text { tients in the traction group with a mental } \\
\text { test score of } 0 \text { was two, while the number } \\
\text { in the no-traction group was } 37 . "\end{array}$ \\
\hline Free of performance bias? & Unclear risk & $\begin{array}{l}\text { Mention in Nursing Times article report- } \\
\text { ing on experience at trial hospital site that } \\
\text { "The traction study, however, was seen as a } \\
\text { hindrance because, in the absence of the re- } \\
\text { searchers, ward staff were expected to apply } \\
\text { skin traction. Staff had [initial] difficulty } \\
\text { with this as they felt skin traction preju- } \\
\text { diced skin integrity." }\end{array}$ \\
\hline
\end{tabular}

Finsen 1992

Methods

Participants
Randomised by the use of random numbers.

38 post-randomisation exclusions: 21 impacted fractures, 17 who had surgery within 6 hours of admission

118 people with a proximal femoral fracture

Hospital in Orkanger, Norway

Period of study: not stated

Mean age: 79 years

Female: $74 \%$

Intracapsular fractures: $58 \%$

Assigned: ?/?/? 
Finsen 1992 (Continued)

Assessed: 26/29/25 [skin traction / skeletal traction / control]

\begin{tabular}{l|l}
\hline Interventions & $\begin{array}{l}\text { Pre-operative skin traction using } 3 \mathrm{~kg} \text { weight of traction applied via a pulley at the end } \\
\text { of the bed versus pre-operative skeletal traction (10\% of body weight) applied via a } \\
\text { Steinman pin versus those nursed free in bed (injured leg placed on pillow) }\end{array}$ \\
\hline Outcomes & $\begin{array}{l}\text { Length of follow-up: included surgery; analgesic data for } 24 \text { hours } \\
\text { Analgesic consumption } \\
\text { Time taken in fracture reduction } \\
\text { Operation time } \\
\text { Operative blood loss } \\
\text { Mortality }\end{array}$ \\
\hline Notes & Reply received: no new information \\
\hline
\end{tabular}

Risk of bias

\begin{tabular}{|c|c|c|}
\hline Bias & Authors' judgement & Support for judgement \\
\hline $\begin{array}{l}\text { Random sequence generation (selection } \\
\text { bias) }\end{array}$ & Low risk & $\begin{array}{l}\text { "On admission they were allocated with the } \\
\text { aid of random numbers to one of three pre- } \\
\text { operative treatment groups." }\end{array}$ \\
\hline Allocation concealment (selection bias) & Unclear risk & No details given \\
\hline $\begin{array}{l}\text { Blinding (performance bias and detection } \\
\text { bias) } \\
\text { Subjective outcomes }\end{array}$ & High risk & $\begin{array}{l}\text { No indication of blinding. Note though } \\
\text { that "Analgesic medication was standard- } \\
\text { ized and recorded." }\end{array}$ \\
\hline $\begin{array}{l}\text { Blinding (performance bias and detection } \\
\text { bias) } \\
\text { Objective outcomes }\end{array}$ & Unclear risk & $\begin{array}{l}\text { Unlikely to be affected: mortality, duration } \\
\text { of operation, bleeding }\end{array}$ \\
\hline $\begin{array}{l}\text { Incomplete outcome data (attrition bias) } \\
\text { Short term outcomes }\end{array}$ & High risk & $\begin{array}{l}\text { While "five people were not treated accord- } \\
\text { ing to protocol", "all protocol deviants were } \\
\text { retained in their intended group for evalu- } \\
\text { ation of the results." } \\
\text { However, given randomisation was on ad- } \\
\text { mission, it is possible that the exclusion } \\
\text { of " } 17 \text { patients who underwent operation } \\
\text { within } 6 \text { h of admission" was after randomi- } \\
\text { sation. The same may apply to } 21 \text { patients } \\
\text { excluded because they had impacted frac- } \\
\text { tures }\end{array}$ \\
\hline $\begin{array}{l}\text { Incomplete outcome data (attrition bias) } \\
\text { Post-operative outcomes }\end{array}$ & Unclear risk & No report of these outcomes \\
\hline
\end{tabular}


Finsen 1992 (Continued)

\begin{tabular}{l|l|l}
\hline Selective reporting (reporting bias) & High risk & $\begin{array}{l}\text { No protocol. Unclear information on ex- } \\
\text { clusion criteria. }\end{array}$ \\
\hline Balanced baseline characteristics? & Unclear risk & $\begin{array}{l}\text { Baseline data may not have been provided } \\
\text { for all randomised patients. Otherwise, } \\
\text { similar baseline characteristics in the three } \\
\text { groups aside from "the proportion of pa- } \\
\text { tients who had received analgesic medica- } \\
\text { tion before admission was somewhat higher } \\
\text { in the skeletal traction group than in the } \\
\text { other two groups" }\end{array}$ \\
\hline Free of performance bias? & Unclear risk & $\begin{array}{l}\text { Mean time to surgery was comparable in } \\
\text { the three groups but no mention of opera- } \\
\text { tor or surgeons experience }\end{array}$ \\
\hline
\end{tabular}

\section{Ghnaimat 2005}

\begin{tabular}{ll}
\hline Methods & Randomised by last digit of hospital admission number. \\
\hline Participants & 74 people with a proximal femoral fracture \\
& Hospital in Zarqa, Jordan \\
Period of study: February 2002 to October 2004 \\
Excluded: patients refusing consent, patients with conditions which contraindicated the \\
use of skin traction: e.g. skin ulceration, severe oedema or peripheral arterial disease, \\
lower limb deformities, allergy to adhesive bandages \\
Mean age: 73 years \\
Females: $57 \%$ (see Notes) \\
Intracapsular fractures: $19 \%$ (see Notes) \\
Assigned: $36 / 38$ [traction / control] \\
\hline
\end{tabular}

Interventions

Pre-operative skin traction using $6 \mathrm{lb}$ weight of traction applied via longitudinal traction versus those nursed free in bed (exact method of nursing the injured limb not specified)

$\begin{array}{ll}\text { Lutcomes } & \text { Length of follow-up: unknown (until discharge or up to } 7 \text { days?) } \\ \text { Daily pain scores (visual analogue score } 0 \text { [no pain] to } 10 \text { [worst pain]) } \\ \text { Analgesic use on days } 1 \text { to } 7 \\ \text { Pressure sores (grades } 1 \text { and 2; no mention of classification system) } \\ \text { Difficulty in fracture reduction (see Notes) } \\ \text { Complications related to traction } \\ \text { Length of hospital stay }\end{array}$

Notes

Text and tables contradictory for sex ratio, present values are calculated from the text (ratio female to male: $2 / 1.5$ ). This also applied to the number of intracapsular fractures, again the number in the text was used in the review.

Percentages given for the fracture reduction results do not tally with the numbers randomised.

Pain scale direction inferred. 
Ghnaimat 2005 (Continued)

\section{Risk of bias}

\begin{tabular}{|c|c|c|}
\hline Bias & Authors' judgement & Support for judgement \\
\hline $\begin{array}{l}\text { Random sequence generation (selection } \\
\text { bias) }\end{array}$ & High risk & $\begin{array}{l}\text { "patients with odd admission numbers re- } \\
\text { ceived skin traction and those with even } \\
\text { numbers were nursed in bed without skin } \\
\text { traction." }\end{array}$ \\
\hline Allocation concealment (selection bias) & High risk & $\begin{array}{l}\text { Quasi-randomised - based on hospital ad- } \\
\text { mission number. }\end{array}$ \\
\hline $\begin{array}{l}\text { Blinding (performance bias and detection } \\
\text { bias) } \\
\text { Subjective outcomes }\end{array}$ & High risk & $\begin{array}{l}\text { "A subjective evaluation about the ease of } \\
\text { reduction or performing hemiarthroplasty } \\
\text { was done by a senior surgeon who was not } \\
\text { informed about which patient received pre- } \\
\text { operative skin traction." But no indication } \\
\text { of safeguards and only for ease of reduction }\end{array}$ \\
\hline $\begin{array}{l}\text { Blinding (performance bias and detection } \\
\text { bias) } \\
\text { Objective outcomes }\end{array}$ & Low risk & $\begin{array}{l}\text { Length of stay reported - less likely to be at } \\
\text { risk of bias. }\end{array}$ \\
\hline $\begin{array}{l}\text { Incomplete outcome data (attrition bias) } \\
\text { Short term outcomes }\end{array}$ & High risk & $\begin{array}{l}\text { Incomplete data and inconsistent percent- } \\
\text { ages. }\end{array}$ \\
\hline $\begin{array}{l}\text { Incomplete outcome data (attrition bias) } \\
\text { Post-operative outcomes }\end{array}$ & High risk & Incomplete data \\
\hline Selective reporting (reporting bias) & High risk & $\begin{array}{l}\text { No protocol and some concerns regarding } \\
\text { reporting of outcomes }\end{array}$ \\
\hline Balanced baseline characteristics? & Low risk & $\begin{array}{l}\text { Probably OK - balance in age, gender, frac- } \\
\text { ture type and pressure sores }\end{array}$ \\
\hline Free of performance bias? & Unclear risk & $\begin{array}{l}\text { No statements on this. Time to surgery ap- } \\
\text { peared similar in the two groups. This may } \\
\text { apply also to surgical experience }\end{array}$ \\
\hline
\end{tabular}

\section{Jerre 2000}

\section{Methods}

Participants
Randomised by sealed opaque envelopes and involving the use of a telephone line. No post-randomisation exclusions.

120 people with a proximal femoral fracture

Hospital in Goteborg, Sweden

Period of study: not stated 
Mean age: 80 years (range 50 to 96 )

Female: $76 \%$

Intracapsular fractures: $50 \%$

Assigned: 60/60 [traction / control]

Interventions

Pre-operative skin traction using $3 \mathrm{~kg}$ weight of traction applied to the leg via a foam rubber boot and straps and the leg placed in a traction sled versus those nursed free in bed (exact method of nursing the injured limb not specified)

\begin{tabular}{|c|c|}
\hline Outcomes & $\begin{array}{l}\text { Length of follow-up: } 4 \text { months } \\
\text { Pain scores (visual analogue scale: } 0 \text { [pain-free] to } 10 \text { [worst pain imaginable]) at } 1,4 \\
\text { and } 12 \text { hours after 'treatment' (application of traction or allocation to control group) } \\
\text { Supplementary analgesic consumption } \\
\text { Pre-operative complications (pressure sores: all grade 1; classification system not stated) } \\
\text { Post-operative complications (e.g. urinary tract infections, red spots, pressure sores) } \\
\text { Fracture healing complications } \\
\text { Quality of fracture reduction } \\
\text { Wound infection } \\
\text { Thrombosis } \\
\text { Fracture compression } \\
\text { Mortality }\end{array}$ \\
\hline Notes & $\begin{array}{l}\text { Reply from authors of trial with supplementary information of trial methodology and } \\
\text { results. } 30 \text { cervical fractures and } 30 \text { trochanteric fractures were allocated to traction and } \\
30 \text { cervical fractures and } 30 \text { trochanteric fractures to 'no traction' }\end{array}$ \\
\hline
\end{tabular}

Risk of bias

\begin{tabular}{|c|c|c|}
\hline Bias & Authors' judgement & Support for judgement \\
\hline $\begin{array}{l}\text { Random sequence generation (selection } \\
\text { bias) }\end{array}$ & Unclear risk & $\begin{array}{l}\text { Randomised. "sealed opaque envelope" } \\
\text { (personal communication) }\end{array}$ \\
\hline Allocation concealment (selection bias) & Low risk & $\begin{array}{l}\text { "sealed opaque envelope and telephone } \\
\text { line" Inexact details of process but seems } \\
\text { likely that allocation was concealed }\end{array}$ \\
\hline $\begin{array}{l}\text { Blinding (performance bias and detection } \\
\text { bias) } \\
\text { Subjective outcomes }\end{array}$ & High risk & No mention of blinding. \\
\hline
\end{tabular}

Blinding (performance bias and detection Unclear risk bias)

Objective outcomes
No mention of blinding, but for the outcomes measured (operative time, fracture healing and ease of reduction), lack of blinding is unlikely to be important 
Jerre 2000 (Continued)

\begin{tabular}{l|l|l}
\hline $\begin{array}{l}\text { Incomplete outcome data (attrition bias) } \\
\text { Post-operative outcomes }\end{array}$ & Low risk & Few lost to follow-up. Reasonable balance. \\
\hline Selective reporting (reporting bias) & Unclear risk & No protocol available \\
\hline Balanced baseline characteristics? & Unclear risk & $\begin{array}{l}\text { Well matched groups in terms of age, sex } \\
\text { and fracture types but no information on } \\
\text { co-morbidities }\end{array}$ \\
\hline Free of performance bias? & Low risk & $\begin{array}{l}\text { Comparable time to operation and care } \\
\text { programmes }\end{array}$ \\
\hline
\end{tabular}

\section{Needoff 1993}

\begin{tabular}{ll} 
Methods & $\begin{array}{l}\text { Randomisation based on case note number. } \\
3 \text { post-randomisation exclusions: not operated on. }\end{array}$ \\
\hline Participants & 67 people with a proximal femoral fracture \\
& Hospital in Nottingham, UK \\
Period of study: not stated & Excluded: 33 patients with mini-mental state examination score of 23 or less out of 30 \\
points & Mean age: 78 years \\
Female: $77 \%$ \\
Intracapsular fractures: $50 \%$ \\
Assigned: $32 / 35$ [traction / control]
\end{tabular}

Interventions

Pre-operative skin traction using $2.5 \mathrm{~kg}$ weight of traction applied via skin traction over a pulley at the end of the bed versus those nursed free in bed (injured leg in comfortable position - flexion, abduction and external rotation - with pillow under thigh)

\begin{tabular}{ll} 
Outcomes & $\begin{array}{l}\text { Length of follow-up: unknown (2 days?) } \\
\text { Pain scores (visual analogue scale: } 0 \text { (pain-free) to } 10 \text { (worst pain possible)) } \\
\text { Analgesic consumption } \\
\text { Pressure sores (no description of classification system or monitoring of these) } \\
\text { Operating time }\end{array}$ \\
\hline Notes & $\begin{array}{l}\text { Reply received: method of randomisation, no difference in care programmes, or pressure } \\
\text { sores }\end{array}$ \\
\hline
\end{tabular}

\section{Risk of bias}

\begin{tabular}{|c|c|c|}
\hline Bias & Authors' judgement & Support for judgement \\
\hline $\begin{array}{l}\text { Random sequence generation (selection } \\
\text { bias) }\end{array}$ & High risk & $\begin{array}{l}\text { "Case home number" (personal communi- } \\
\text { cation) }\end{array}$ \\
\hline
\end{tabular}


Needoff 1993 (Continued)

\begin{tabular}{|c|c|c|}
\hline Allocation concealment (selection bias) & High risk & $\begin{array}{l}\text { "Case home number" (personal communi- } \\
\text { cation) }\end{array}$ \\
\hline $\begin{array}{l}\text { Blinding (performance bias and detection } \\
\text { bias) } \\
\text { Subjective outcomes }\end{array}$ & High risk & No mention. \\
\hline $\begin{array}{l}\text { Blinding (performance bias and detection } \\
\text { bias) } \\
\text { Objective outcomes }\end{array}$ & Unclear risk & $\begin{array}{l}\text { No report of these measures, except opera- } \\
\text { tion time. }\end{array}$ \\
\hline $\begin{array}{l}\text { Incomplete outcome data (attrition bias) } \\
\text { Short term outcomes }\end{array}$ & High risk & Active surveillance but incomplete data. \\
\hline $\begin{array}{l}\text { Incomplete outcome data (attrition bias) } \\
\text { Post-operative outcomes }\end{array}$ & High risk & As above. No data provided. \\
\hline Selective reporting (reporting bias) & High risk & $\begin{array}{l}\text { Well set up but no protocol and changes in } \\
\text { outcome collection (no long term data) }\end{array}$ \\
\hline Balanced baseline characteristics? & Unclear risk & $\begin{array}{l}\text { Balanced age, gender, mental text scores, } \\
\text { fracture type, pain at admission }\end{array}$ \\
\hline Free of performance bias? & Low risk & $\begin{array}{l}\text { Attempt at standardisation in terms of pain } \\
\text { medication and assessment }\end{array}$ \\
\hline
\end{tabular}

Resch 1998

Methods

Randomised by closed envelopes. After X-ray diagnosis, the nurse in the emergency department taking care of the patient drew an envelope from a pre-prepared set of closed envelopes

\begin{tabular}{|c|c|}
\hline Participants & $\begin{array}{l}78 \text { people with a displaced proximal femoral fracture } \\
\text { Hospital in Lund, Sweden } \\
\text { Period of study: not stated } \\
\text { Excluded: } 75 \text { patients were excluded mainly due to senile confusion. refusal to participate } \\
\text { and skin problems such as leg ulcers. } \\
\text { Mean age: } 81 \text { years } \\
\text { Female: } 73 \% \\
\text { Intracapsular fractures: } 55 \% \\
\text { Assigned: } 40 / 38 \text { [skin traction / skeletal traction] }\end{array}$ \\
\hline Interventions & $\begin{array}{l}\text { Pre-operative skin traction using } 3 \mathrm{~kg} \text { weight of traction applied to the leg via a foam } \\
\text { rubber boot and straps and the leg placed in a traction sled versus pre-operative skeletal } \\
\text { traction ( } 5 \% \text { to } 10 \% \text { of body weight) applied via a K-wire though the proximal tibia }\end{array}$ \\
\hline
\end{tabular}


Resch 1998 (Continued)

\begin{tabular}{ll}
\hline Outcomes & $\begin{array}{l}\text { Length of follow-up: } 3 \text { to } 4 \text { days } \\
\text { Pain scores (visual analogue scale: } 0 \text { [pain-free] to } 10 \text { [worst pain imaginable]) } \\
\text { Use of analgesics } \\
\text { Complications related to traction } \\
\text { Length of operation } \\
\text { Time spent in hospital departments }\end{array}$ \\
\hline Notes & $\begin{array}{l}\text { Abstract only available for the first version of review. } \\
\text { Small discrepancies in denominators for numbers of participants who found the appli- } \\
\text { cation of traction painful. Text gives } 7 / 35 \text { versus } 16 / 43 . \text { Possible intention-to-treat prob- } \\
\text { lem but also could be results for trochanteric (35) versus cervical (43) fractures. Results } \\
\text { from abstract (and summary of full report) retained for this outcome. } \\
\text { Information on method of randomisation received indirectly from authors. Also confir- } \\
\text { mation that no patient was lost to follow-up }\end{array}$ \\
\hline
\end{tabular}

Risk of bias

\begin{tabular}{|l|l|l}
\hline Bias & Authors' judgement & Support for judgement \\
\hline $\begin{array}{l}\text { Random sequence generation (selection } \\
\text { bias) }\end{array}$ & Unclear risk & $\begin{array}{l}\text { "closed envelopes" (personal communica- } \\
\text { tion) } \\
\text { Randomised by closed envelopes. After X- } \\
\text { ray diagnosis, the nurse in the emergency } \\
\text { department taking care of the patient drew } \\
\text { an envelope from a pre-prepared set of } \\
\text { closed envelopes. (personal communica- } \\
\text { tion) }\end{array}$ \\
\hline Allocation concealment (selection bias) & Unclear risk & $\begin{array}{l}\text { "closed envelopes" (personal communica- } \\
\text { tion) } \\
\text { Randomised by closed envelopes. After X- } \\
\text { ray diagnosis, the nurse in the emergency } \\
\text { department taking care of the patient drew } \\
\text { an envelope from a pre-prepared set of } \\
\text { closed envelopes. (personal communica- } \\
\text { tion) }\end{array}$ \\
\hline
\end{tabular}

Blinding (performance bias and detection High risk

No blinding mentioned

bias)

Subjective outcomes

Blinding (performance bias and detection Unclear risk bias)

Objective outcomes

Incomplete outcome data (attrition bias) High risk

Short term outcomes
Unresolved discrepancies regarding percentages and numbers available at followup 
Resch 1998 (Continued)

\begin{tabular}{l|l|l}
\hline $\begin{array}{l}\text { Incomplete outcome data (attrition bias) } \\
\text { Post-operative outcomes }\end{array}$ & High risk & $\begin{array}{l}\text { [Complications from chart review and on } \\
\text { ward.] Uncertain about risk of bias }\end{array}$ \\
\hline Selective reporting (reporting bias) & Unclear risk & $\begin{array}{l}\text { No protocol available - although some con- } \\
\text { sistency with approach in the two trials }\end{array}$ \\
\hline Balanced baseline characteristics? & Unclear risk & $\begin{array}{l}\text { Balanced regarding gender, fracture type, } \\
\text { initial pain but no information otherwise }\end{array}$ \\
\hline Free of performance bias? & Unclear risk & $\begin{array}{l}\text { Comparable in time to operation and fol- } \\
\text { low-up, but insufficient to tell }\end{array}$ \\
\hline
\end{tabular}

Resch 2005

\begin{tabular}{ll} 
Methods & $\begin{array}{l}\text { Randomised by closed envelopes. After X-ray diagnosis, the nurse in the emergency } \\
\text { department taking care of the patient drew an envelope from a pre-prepared set of closed } \\
\text { envelopes. Queried imbalance in the numbers in the } 3 \text { intervention groups with the } \\
\text { trialists but this remained unexplained }(49 ; 21 ; 53)\end{array}$ \\
\hline Participants & 123 people with a displaced proximal femoral fracture \\
Hospital in Lund, Sweden \\
Period of study: not stated \\
Excluded: patients unable to give informed consent; local problems that would prohibit \\
the use of skin traction such as ulcers, eczema or perivascular disease \\
Mean age: 81 years \\
Female: $73 \%$ \\
Intracapsular fractures: $46 \%$ \\
Assigned: $49 / 21 / 53$ [skin traction / Lasse pillow / control]
\end{tabular}

Interventions

Pre-operative skin traction using $3 \mathrm{~kg}$ weight of traction applied to the leg via a foam rubber boot and straps and the leg placed in a traction sled versus those with their lower leg placed in a special foam pillow (Lasse pillow) that allowed some movement while preventing inadvertent movement of the injured leg versus those nursed free in bed (injured leg in resting position with pillow placed under thigh).

Leg position - 30 degrees flexion and slight outward rotation of the hip and supported by pillows - same in the 3 groups

Length of follow-up: 3 to 4 days
Pain scores (visual analogue scale: 0 [pain-free] to 10 [worst pain imaginable])
Use of analgesics
Complications (erythema (2), oedema (1) and paraesthesia (1))
Length of operation
Time spent in hospital departments

Possible intention-to-treat problem. Reply received: method of randomisation, some baseline characteristics and complications split by treatment group 
Resch 2005 (Continued)

\section{Risk of bias}

\begin{tabular}{|c|c|c|}
\hline Bias & Authors' judgement & Support for judgement \\
\hline $\begin{array}{l}\text { Random sequence generation (selection } \\
\text { bias) }\end{array}$ & Unclear risk & $\begin{array}{l}\text { "closed envelopes" (personal communica- } \\
\text { tion) } \\
\text { Randomised by closed envelopes. After X- } \\
\text { ray diagnosis, the nurse in the emergency } \\
\text { department taking care of the patient drew } \\
\text { an envelope from a pre-prepared set of } \\
\text { closed envelopes. (personal communica- } \\
\text { tion) }\end{array}$ \\
\hline Allocation concealment (selection bias) & Unclear risk & $\begin{array}{l}\text { closed envelopes" Randomised by closed } \\
\text { envelopes. After X-ray diagnosis, the nurse } \\
\text { in the emergency department taking care } \\
\text { of the patient drew an envelope from a pre- } \\
\text { prepared set of closed envelopes. (personal } \\
\text { communication }\end{array}$ \\
\hline $\begin{array}{l}\text { Blinding (performance bias and detection } \\
\text { bias) } \\
\text { Subjective outcomes }\end{array}$ & High risk & No blinding mentioned \\
\hline $\begin{array}{l}\text { Blinding (performance bias and detection } \\
\text { bias) } \\
\text { Objective outcomes }\end{array}$ & Unclear risk & No blinding but uncertain risk of bias \\
\hline $\begin{array}{l}\text { Incomplete outcome data (attrition bias) } \\
\text { Short term outcomes }\end{array}$ & High risk & $\begin{array}{l}\text { Unresolved discrepancies including num- } \\
\text { bers randomised }\end{array}$ \\
\hline $\begin{array}{l}\text { Incomplete outcome data (attrition bias) } \\
\text { Post-operative outcomes }\end{array}$ & Unclear risk & Complications data obtained \\
\hline Selective reporting (reporting bias) & Unclear risk & $\begin{array}{l}\text { No protocol available - although some con- } \\
\text { sistency with approach in the two trials }\end{array}$ \\
\hline Balanced baseline characteristics? & Unclear risk & $\begin{array}{l}\text { Balanced regarding pain but no informa- } \\
\text { tion on population }\end{array}$ \\
\hline Free of performance bias? & Unclear risk & $\begin{array}{l}\text { Comparable in time to operation and fol- } \\
\text { low-up, but insufficient to tell }\end{array}$ \\
\hline
\end{tabular}


Rosen 2001

\begin{tabular}{ll} 
Methods & $\begin{array}{l}\text { Randomised using a computer programme to randomly assign } 100 \text { sequential 'slots' to } \\
\# 1 \text { or } \# 2 ; \text { these were then assigned as traction or pillow }\end{array}$ \\
\hline Participants & 100 people with a proximal femoral fracture \\
& $\begin{array}{l}\text { Hospital in New York, USA } \\
\text { Period of study: June } 1995 \text { to February } 1997 \\
\text { Excluded: patients younger than } 50 \text { years of age, underlying dementia, other concomitant } \\
\text { injury, presentation more than } 24 \text { hours after the initial injury. Patients had to have } \\
\text { adequate cognitive function to be considered for inclusion. } \\
\text { Mean age: } 78 \text { years (range } 50-97 \text { years) }\end{array}$ \\
Female: $78 \%$ \\
Intracapsular fractures: $55 \%$ (in text), $43 \%$ (in table) \\
Assigned: $50 / 50$ [traction / control]
\end{tabular}

Interventions

Pre-operative skin traction using 5 pounds weight of traction applied via a foam traction boot versus those nursed free in bed (injured leg in resting position with pillow placed under thigh)

Outcomes

Length of follow-up: till surgery

Pain scores (visual analogue scale: 0 [no pain] to 10 [extreme pain]): 15 minutes after application traction or leg rested on pillows and the following morning.

Pain on application traction/rest on pillows

Analgesic consumption

Complications of traction

Notes

Reply received: method of randomisation, all patients received allocated treatment, identical pre-operative care

\section{Risk of bias}

\begin{tabular}{|c|c|c|}
\hline Bias & Authors' judgement & Support for judgement \\
\hline $\begin{array}{l}\text { Random sequence generation (selection } \\
\text { bias) }\end{array}$ & Low risk & $\begin{array}{l}\text { "randomization was performed using a } \\
\text { computer-generated program" }\end{array}$ \\
\hline Allocation concealment (selection bias) & Unclear risk & No other details given. \\
\hline $\begin{array}{l}\text { Blinding (performance bias and detection } \\
\text { bias) } \\
\text { Subjective outcomes }\end{array}$ & High risk & No blinding. \\
\hline
\end{tabular}

Blinding (performance bias and detection Unclear risk bias)

Objective outcomes

These outcomes were not assessed.

Incomplete outcome data (attrition bias) Unclear risk

Short term outcomes
Some discrepancies in the data (pain at baseline $\&$ types of fracture) 
Rosen 2001 (Continued)

\begin{tabular}{l|l|l}
\hline $\begin{array}{l}\text { Incomplete outcome data (attrition bias) } \\
\text { Post-operative outcomes }\end{array}$ & Unclear risk & Outcomes not assessed. \\
\hline Selective reporting (reporting bias) & Unclear risk & No protocol available. \\
\hline Balanced baseline characteristics? & Low risk & $\begin{array}{l}\text { Groups were well matched with respect to } \\
\text { baseline data, including initial pain }\end{array}$ \\
\hline Free of performance bias? & Low risk & $\begin{array}{l}\text { Active, standardised medication and fol- } \\
\text { low-up; similar time to operation }\end{array}$ \\
\hline
\end{tabular}

Saygi 2010

\begin{tabular}{|c|c|c|}
\hline Methods & \multicolumn{2}{|c|}{ Randomised by order of admission to the hospital } \\
\hline Participants & \multicolumn{2}{|c|}{$\begin{array}{l}108 \text { people with a proximal femoral fracture } \\
\text { Two hospitals in Istanbul, Turkey } \\
\text { Excluded: patients refusing consent, patients with cognitive inadequacy } \\
\text { Mean age: } 76 \text { (range } 19 \text { to } 100 \text { ) } \\
\text { Females: } 67 \% \\
\text { Intracapsular fractures: } 44 \% \\
\text { Assigned: } 36 / 36 / 36 \text { [traction / placebo traction / control] }\end{array}$} \\
\hline Interventions & \multicolumn{2}{|c|}{$\begin{array}{l}\text { Pre-operative skin traction using } 2 \mathrm{~kg} \text { weight of traction along with a pillow beneath the } \\
\text { leg versus application of skin traction without the use of weights along with a pillow } \\
\text { beneath the injured leg versus pillow placed beneath the injured leg }\end{array}$} \\
\hline Outcomes & \multicolumn{2}{|c|}{$\begin{array}{l}\text { Length of follow-up: unclear (up to operation?) } \\
\text { Pain scores (visual analogue scale: } 0 \text { [no pain] to } 10 \text { [worst pain]): } 1,4 \text { and } 12 \text { hours } \\
\text { after application } \\
\text { Number of analgesic injections / day } \\
\text { Adverse effects: pressure sores and neuropraxia }\end{array}$} \\
\hline Notes & \multicolumn{2}{|c|}{$\begin{array}{l}\text { Timing of follow-up and measurement of adverse outcomes were not described in the } \\
\text { trial methods }\end{array}$} \\
\hline \multicolumn{3}{|l|}{ Risk of bias } \\
\hline Bias & Authors' judgement & Support for judgement \\
\hline $\begin{array}{l}\text { Random sequence generation (selection } \\
\text { bias) }\end{array}$ & High risk & $\begin{array}{l}\text { "The } 108 \text { patients who participated in the } \\
\text { study were randomly allocated into three } \\
\text { groups, according to the order of admission } \\
\text { to the hospital." }\end{array}$ \\
\hline Allocation concealment (selection bias) & High risk & As above. Quasi-randomised method. \\
\hline
\end{tabular}




\section{Saygi 2010 (Continued)}

\begin{tabular}{|c|c|c|}
\hline $\begin{array}{l}\text { Blinding (performance bias and detection } \\
\text { bias) } \\
\text { Subjective outcomes }\end{array}$ & High risk & No mention of blinding \\
\hline $\begin{array}{l}\text { Blinding (performance bias and detection } \\
\text { bias) } \\
\text { Objective outcomes }\end{array}$ & Unclear risk & $\begin{array}{l}\text { Unclear risk of bias from lack of blinding } \\
\text { of adverse effects }\end{array}$ \\
\hline $\begin{array}{l}\text { Incomplete outcome data (attrition bias) } \\
\text { Short term outcomes }\end{array}$ & Low risk & $\begin{array}{l}\text { Pre-randomisation exclusions given - seven } \\
\text { patients excluded due to refusal to give con- } \\
\text { sent or cognitive inadequacy. Loss of fol- } \\
\text { low-up unlikely }\end{array}$ \\
\hline $\begin{array}{l}\text { Incomplete outcome data (attrition bias) } \\
\text { Post-operative outcomes }\end{array}$ & Unclear risk & No post-op outcomes \\
\hline Selective reporting (reporting bias) & Unclear risk & No protocol available. \\
\hline Balanced baseline characteristics? & Unclear risk & $\begin{array}{l}\text { Groups were well matched with respect to } \\
\text { age, sex and type of fracture. No mention } \\
\text { of medical co-morbidities }\end{array}$ \\
\hline Free of performance bias? & Low risk & $\begin{array}{l}\text { "Anti-thrombotic prophylaxis was rou- } \\
\text { tinely administered to all patients. The } \\
\text { patients also received paracetamol tablets } \\
\text { orally 3-times a day routinely." Time to } \\
\text { operation was similar in the three groups } \\
\text { (mean } 53.2 \text { hours for whole population) }\end{array}$ \\
\hline
\end{tabular}

\section{Yip 2002}

\begin{tabular}{ll}
\hline Methods & Randomised by last digit of patient's registration number. \\
\hline Participants & 311 people with a proximal femoral fracture \\
& Hospital in Hong Kong, China \\
& Period of study: August 1995 to December 1997 \\
& Excluded: patients with senile dementia or taking regular analgesia prior to admission \\
& Mean age: 79 years \\
& Females: $66 \%$ \\
& Intracapsular fractures: \% not stated \\
& Assigned: $166 / 145$ [traction / control] \\
\hline
\end{tabular}

Interventions

Pre-operative skin traction using $2 \mathrm{~kg}$ weight of traction applied via a foam boot versus those nursed free in bed (injured leg placed on pillow)

Outcomes

Length of follow up: one year (however, only data up to one week from admission were presented). 
Yip 2002 (Continued)

Pain scores (visual analogue score: 0 [no pain] to 2 [worst pain]) assessed 4 times each day pre-operatively

Analgesic use pre-operatively

Operative blood loss

Operative time

Complications (no description of recording of these, including the monitoring of pressure sores)

Reply received: no difference in care programmes, confirmation of no loss to follow-up, no pressure sores, full results for operative time.

Top end (2) of pain scale inferred from graph in article.

\section{Risk of bias}

\begin{tabular}{|c|c|c|}
\hline Bias & Authors' judgement & Support for judgement \\
\hline $\begin{array}{l}\text { Random sequence generation (selection } \\
\text { bias) }\end{array}$ & High risk & $\begin{array}{l}\text { "Patients were randomised into two study } \\
\text { arms depending on whether their hospi- } \\
\text { tal admission number was an odd or even } \\
\text { number" }\end{array}$ \\
\hline Allocation concealment (selection bias) & High risk & $\begin{array}{l}\text { Quasi-randomised - based on hospital reg- } \\
\text { istration number. }\end{array}$ \\
\hline $\begin{array}{l}\text { Blinding (performance bias and detection } \\
\text { bias) } \\
\text { Subjective outcomes }\end{array}$ & High risk & $\begin{array}{l}\text { No mention in paper. Assessor blinding } \\
\text { claimed in an email from the trial investi- } \\
\text { gator but with no supporting evidence. A } \\
\text { research assistant collected the data, }\end{array}$ \\
\hline $\begin{array}{l}\text { Blinding (performance bias and detection } \\
\text { bias) } \\
\text { Objective outcomes }\end{array}$ & Unclear risk & Outcomes were not assessed. \\
\hline $\begin{array}{l}\text { Incomplete outcome data (attrition bias) } \\
\text { Short term outcomes }\end{array}$ & Unclear risk & Lack of unable data. No pressure sores? \\
\hline $\begin{array}{l}\text { Incomplete outcome data (attrition bias) } \\
\text { Post-operative outcomes }\end{array}$ & Unclear risk & Outcomes not assessed. \\
\hline Selective reporting (reporting bias) & Unclear risk & $\begin{array}{l}\text { No protocol although study appeared well } \\
\text { set up. }\end{array}$ \\
\hline Balanced baseline characteristics? & Unclear risk & $\begin{array}{l}\text { Groups were well matched in age and sex. } \\
\text { There was a discrepancy in the numbers } \\
\text { for each group ( } 166 \mathrm{v} 145) \text { which proba- } \\
\text { bly reflects the inadequate randomisation } \\
\text { methodology. No mention of co-morbidi- } \\
\text { ties }\end{array}$ \\
\hline
\end{tabular}


Yip 2002 (Continued) 
DATA AND ANALYSES

Comparison 1. Pre-operative traction versus no traction

$\begin{array}{llccc}\text { Outcome or subgroup title } & \begin{array}{c}\text { No. of } \\ \text { studies }\end{array} & \begin{array}{c}\text { No. of } \\ \text { participants }\end{array} & \text { Statistical method } & \text { Effect size }\end{array}$

\begin{tabular}{|c|c|c|c|c|}
\hline $\begin{array}{r}1 \text { Pain (Visual Analogue Scale: 0: } \\
\text { none to 10: worst imaginable) }\end{array}$ & 3 & & Mean Difference (IV, Fixed, 95\% CI) & Subtotals only \\
\hline 1.1 Soon after immobilisation & 3 & 274 & Mean Difference (IV, Fixed, 95\% CI) & $0.11[-0.27,0.50]$ \\
\hline 1.2 At 12 hours & 1 & 72 & Mean Difference (IV, Fixed, 95\% CI) & $0.24[-0.13,0.61]$ \\
\hline $\begin{array}{l}2 \text { Analgesic use on ward } \\
\text { (participants) }\end{array}$ & 2 & & Risk Ratio (M-H, Fixed, 95\% CI) & Totals not selected \\
\hline 2.1 Day 1 & 1 & & Risk Ratio (M-H, Fixed, 95\% CI) & $0.0[0.0,0.0]$ \\
\hline 2.2 Day 2 & 1 & & Risk Ratio (M-H, Fixed, 95\% CI) & $0.0[0.0,0.0]$ \\
\hline 2.3 Until surgery & 1 & & Risk Ratio (M-H, Fixed, 95\% CI) & $0.0[0.0,0.0]$ \\
\hline 2.4 High analgesic use & 1 & & Risk Ratio (M-H, Fixed, 95\% CI) & $0.0[0.0,0.0]$ \\
\hline $\begin{array}{l}3 \text { Analgesic use on ward (doses / } \\
\text { injections) }\end{array}$ & 2 & & Mean Difference (IV, Fixed, 95\% CI) & Totals not selected \\
\hline 3.1 Doses on ward & 1 & & Mean Difference (IV, Fixed, 95\% CI) & $0.0[0.0,0.0]$ \\
\hline 3.2 Injections / day & 1 & & Mean Difference (IV, Fixed, 95\% CI) & $0.0[0.0,0.0]$ \\
\hline 4 Pressure sores & 2 & & Risk Ratio (M-H, Fixed, 95\% CI) & Totals not selected \\
\hline 4.1 Pre-operative & 1 & & Risk Ratio (M-H, Fixed, 95\% CI) & $0.0[0.0,0.0]$ \\
\hline 4.2 Post-operative & 1 & & Risk Ratio (M-H, Fixed, 95\% CI) & $0.0[0.0,0.0]$ \\
\hline 5 Difficulty in fracture reduction & 2 & 183 & Risk Ratio (M-H, Fixed, 95\% CI) & $0.92[0.51,1.67]$ \\
\hline 6 Poor quality fracture reduction & 1 & & Risk Ratio (M-H, Fixed, 95\% CI) & Totals not selected \\
\hline 7 General complications & 3 & & Risk Ratio (M-H, Fixed, 95\% CI) & Totals not selected \\
\hline 7.1 Neurapraxia & 1 & & Risk Ratio (M-H, Fixed, 95\% CI) & $0.0[0.0,0.0]$ \\
\hline $\begin{array}{l}7.2 \text { Post-operative (including } \\
\text { pressure sores) }\end{array}$ & 2 & & Risk Ratio (M-H, Fixed, 95\% CI) & $0.0[0.0,0.0]$ \\
\hline 7.3 Complications at 3-4 days & 1 & & Risk Ratio (M-H, Fixed, 95\% CI) & $0.0[0.0,0.0]$ \\
\hline 8 Fracture fixation failure & 1 & & Risk Ratio (M-H, Fixed, 95\% CI) & Totals not selected \\
\hline 8.1 All fractures & 1 & & Risk Ratio (M-H, Fixed, 95\% CI) & $0.0[0.0,0.0]$ \\
\hline 8.2 Intracapsular fracture & 1 & & Risk Ratio (M-H, Fixed, 95\% CI) & $0.0[0.0,0.0]$ \\
\hline 8.3 Extracapsular fracture & 1 & & Risk Ratio (M-H, Fixed, 95\% CI) & $0.0[0.0,0.0]$ \\
\hline 9 Length of operation (minutes) & 2 & 413 & Mean Difference (IV, Fixed, 95\% CI) & $1.28[-4.82,7.39]$ \\
\hline 10 Intra-operative blood loss (ml) & 1 & & Mean Difference (IV, Fixed, 95\% CI) & Totals not selected \\
\hline 11 Length of hospital stay (days) & 1 & & Mean Difference (IV, Fixed, 95\% CI) & Totals not selected \\
\hline
\end{tabular}


Comparison 2. Traction versus no or 'placebo' traction

\begin{tabular}{|c|c|c|c|c|}
\hline Outcome or subgroup title & $\begin{array}{l}\text { No. of } \\
\text { studies }\end{array}$ & $\begin{array}{c}\text { No. of } \\
\text { participants }\end{array}$ & Statistical method & Effect size \\
\hline $\begin{array}{l}1 \text { Pain (VAS) - soon after } \\
\text { immobilisation }\end{array}$ & 1 & & Mean Difference (IV, Fixed, 95\% CI) & Totals not selected \\
\hline $\begin{array}{l}1.1 \text { 'Placebo' traction - no } \\
\text { weights added }\end{array}$ & 1 & & Mean Difference (IV, Fixed, 95\% CI) & $0.0[0.0,0.0]$ \\
\hline 1.2 No traction - pillow only & 1 & & Mean Difference (IV, Fixed, 95\% CI) & $0.0[0.0,0.0]$ \\
\hline 2 Pain (VAS) - at 12 hours & 1 & & Mean Difference (IV, Fixed, 95\% CI) & Totals not selected \\
\hline $\begin{array}{l}2.1 \text { 'Placebo' traction - no } \\
\text { weights added }\end{array}$ & 1 & & Mean Difference (IV, Fixed, 95\% CI) & $0.0[0.0,0.0]$ \\
\hline 2.2 No traction - pillow only & 1 & & Mean Difference (IV, Fixed, 95\% CI) & $0.0[0.0,0.0]$ \\
\hline 3 Analgesic use - injections / day & 1 & & Mean Difference (IV, Fixed, 95\% CI) & Totals not selected \\
\hline $\begin{array}{l}3.1 \text { 'Placebo' traction - no } \\
\text { weights added }\end{array}$ & 1 & & Mean Difference (IV, Fixed, 95\% CI) & $0.0[0.0,0.0]$ \\
\hline 3.2 No traction - pillow only & 1 & & Mean Difference (IV, Fixed, 95\% CI) & $0.0[0.0,0.0]$ \\
\hline
\end{tabular}

Comparison 3. Skin traction versus skeletal traction

\begin{tabular}{|c|c|c|c|c|}
\hline Outcome or subgroup title & $\begin{array}{l}\text { No. of } \\
\text { studies }\end{array}$ & $\begin{array}{c}\text { No. of } \\
\text { participants }\end{array}$ & Statistical method & Effect size \\
\hline $\begin{array}{l}1 \text { Pain soon after traction (Visual } \\
\text { Analogue Scale: 0: none to } 10 \text { : } \\
\text { worst imaginable) }\end{array}$ & 1 & & Mean Difference (IV, Fixed, 95\% CI) & Totals not selected \\
\hline $\begin{array}{l}2 \text { Analgesic use on ward (number } \\
\text { of doses) }\end{array}$ & 1 & & Mean Difference (IV, Fixed, 95\% CI) & Totals not selected \\
\hline 3 Length of surgery (minutes) & 1 & & Mean Difference (IV, Fixed, 95\% CI) & Totals not selected \\
\hline
\end{tabular}


Analysis I.I. Comparison I Pre-operative traction versus no traction, Outcome I Pain (Visual Analogue Scale: 0: none to 10: worst imaginable).

Review: Pre-operative traction for hip fractures in adults

Comparison: I Pre-operative traction versus no traction

Outcome: I Pain (Visual Analogue Scale: 0: none to 10: worst imaginable)

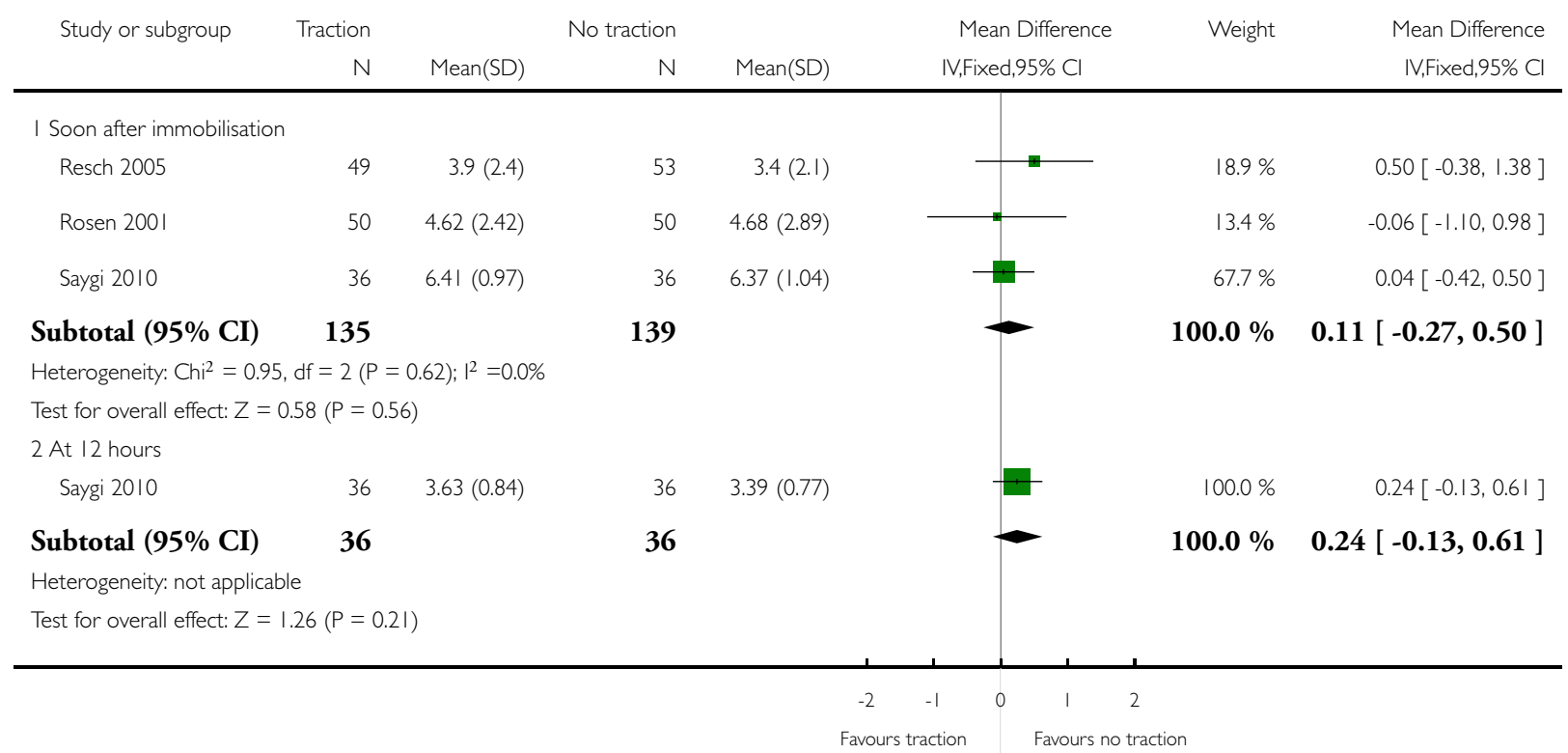


Analysis I.2. Comparison I Pre-operative traction versus no traction, Outcome 2 Analgesic use on ward (participants).

\begin{tabular}{|c|c|c|c|c|}
\hline \multicolumn{5}{|c|}{ Comparison: I Pre-operative traction versus no traction } \\
\hline \multicolumn{5}{|c|}{ Outcome: 2 Analgesic use on ward (participants) } \\
\hline \multirow[t]{2}{*}{ Study or subgroup } & Traction & No traction & \multirow{2}{*}{$\begin{array}{c}\text { Risk Ratio } \\
\text { M-H,Fixed,95\% Cl }\end{array}$} & Risk Ratio \\
\hline & $\mathrm{n} / \mathrm{N}$ & $n / N$ & & M-H,Fixed,95\% Cl \\
\hline \multicolumn{5}{|l|}{ I Day I } \\
\hline Anderson 1993 & $54 / 101$ & $71 / 151$ & + & $1.14[0.89,1.46]$ \\
\hline \multicolumn{5}{|l|}{2 Day 2} \\
\hline Anderson 1993 & $32 / 64$ & $44 / 90$ & - & $1.02[0.74,1.41]$ \\
\hline \multicolumn{5}{|l|}{3 Until surgery } \\
\hline Rosen 2001 & $45 / 50$ & $39 / 50$ & + & $1.15[0.97,1.37]$ \\
\hline \multicolumn{5}{|l|}{4 High analgesic use } \\
\hline Rosen 2001 & $32 / 50$ & $18 / 50$ & 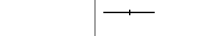 & $1.78[1.16,2.72]$ \\
\hline
\end{tabular}

Analysis I.3. Comparison I Pre-operative traction versus no traction, Outcome 3 Analgesic use on ward (doses / injections).

\footnotetext{
Review: Pre-operative traction for hip fractures in adults

Comparison: I Pre-operative traction versus no traction

Outcome: 3 Analgesic use on ward (doses / injections)
}

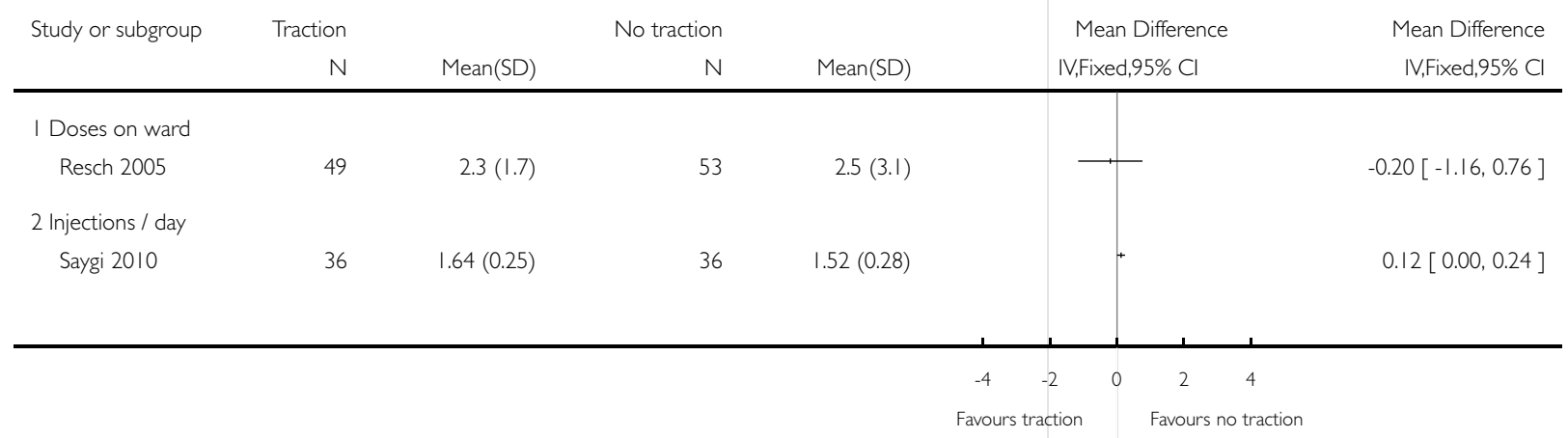


Analysis I.4. Comparison I Pre-operative traction versus no traction, Outcome 4 Pressure sores.

Review: Pre-operative traction for hip fractures in adults

Comparison: I Pre-operative traction versus no traction

Outcome: 4 Pressure sores

\begin{tabular}{|c|c|c|c|c|}
\hline Study or subgroup & $\begin{array}{r}\text { Traction } \\
\mathrm{n} / \mathrm{N}\end{array}$ & $\begin{array}{r}\text { No traction } \\
\mathrm{n} / \mathrm{N}\end{array}$ & $\begin{array}{c}\text { Risk Ratio } \\
\text { M-H,Fixed,95\% Cl }\end{array}$ & $\begin{array}{r}\text { Risk Ratio } \\
\text { M-H,Fixed,95\% Cl }\end{array}$ \\
\hline \multicolumn{5}{|l|}{ I Pre-operative } \\
\hline Jerre 2000 & $5 / 60$ & $0 / 60$ & & $11.00[0.62,194.63]$ \\
\hline \multicolumn{5}{|l|}{2 Post-operative } \\
\hline Saygi 2010 & $2 / 36$ & $0 / 36$ & - & $5.00[0.25,100.63]$ \\
\hline
\end{tabular}

Analysis I.5. Comparison I Pre-operative traction versus no traction, Outcome 5 Difficulty in fracture reduction.

Review: Pre-operative traction for hip fractures in adults

Comparison: I Pre-operative traction versus no traction

Outcome: 5 Difficulty in fracture reduction

\begin{tabular}{|c|c|c|c|c|c|}
\hline \multirow[t]{2}{*}{ Study or subgroup } & Traction & No traction & Risk Ratio & Weight & Risk Ratio \\
\hline & $\mathrm{n} / \mathrm{N}$ & $\mathrm{n} / \mathrm{N}$ & M-H,Fixed,95\% Cl & & M-H,Fixed,95\% Cl \\
\hline Anderson 1993 & $5 / 45$ & $7 / 64$ & $\longrightarrow$ & $33.1 \%$ & $1.02[0.34,3.00]$ \\
\hline Ghnaimat 2005 & $10 / 36$ & $12 / 38$ & & $66.9 \%$ & $0.88[0.43,1.78]$ \\
\hline Total $(95 \%$ CI $)$ & 81 & 102 & & $100.0 \%$ & $0.92[0.51,1.67]$ \\
\hline \multicolumn{6}{|c|}{ Total events: 15 (Traction), 19 (No traction) } \\
\hline \multicolumn{6}{|c|}{ Heterogeneity: $\mathrm{Ch}^{2}=0.05, \mathrm{df}=\mathrm{I}(\mathrm{P}=0.83) ; \mathrm{I}^{2}=0.0 \%$} \\
\hline \multicolumn{6}{|c|}{ Test for overall effect: $Z=0.26(P=0.80)$} \\
\hline \multicolumn{6}{|c|}{ Test for subgroup differences: Not applicable } \\
\hline
\end{tabular}


Analysis I.6. Comparison I Pre-operative traction versus no traction, Outcome 6 Poor quality fracture reduction.

Review: Pre-operative traction for hip fractures in adults

Comparison: I Pre-operative traction versus no traction

Outcome: 6 Poor quality fracture reduction

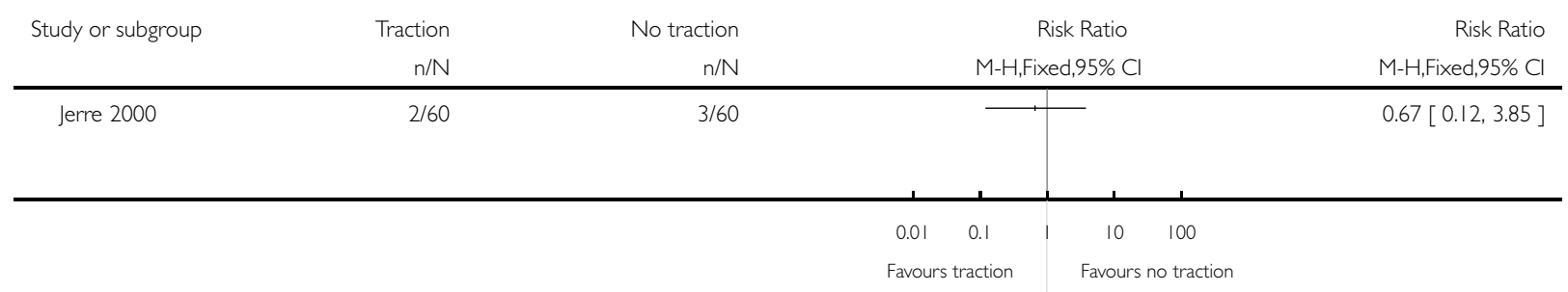

Analysis I.7. Comparison I Pre-operative traction versus no traction, Outcome 7 General complications.

Review: Pre-operative traction for hip fractures in adults

Comparison: I Pre-operative traction versus no traction

Outcome: 7 General complications

\begin{tabular}{|c|c|c|c|c|}
\hline \multirow[t]{2}{*}{ Study or subgroup } & Traction & No traction & $\begin{array}{c}\text { Risk Ratio } \\
\text { M.H Fixed } 95 \%\end{array}$ & $\begin{array}{r}\text { Risk Ratio } \\
\text { M-H Fixed } 95 \%\end{array}$ \\
\hline & $\mathrm{n} / \mathrm{N}$ & $\mathrm{n} / \mathrm{N}$ & M-H,Fixed,95\% Cl & M-H,Fixed,95\% Cl \\
\hline \multicolumn{5}{|l|}{ I Neurapraxia } \\
\hline Saygi 2010 & $1 / 36$ & $0 / 36$ & & $3.00[0.13,71.28]$ \\
\hline \multicolumn{5}{|c|}{2 Post-operative (including pressure sores) } \\
\hline Jerre 2000 & $10 / 60$ & $13 / 60$ & & $0.77[0.37,1.62]$ \\
\hline Saygi 2010 & $3 / 36$ & $0 / 36$ & & $7.00[0.37,130.82]$ \\
\hline \multicolumn{5}{|c|}{3 Complications at 3-4 days } \\
\hline Resch 2005 & $4 / 49$ & $0 / 53$ & & $9.72[0.54,176.00]$ \\
\hline
\end{tabular}

$0.0010 .01 \quad 0.1 \quad 1 \quad 10 \quad 100 \quad 1000$

Favours traction Favours no traction 
Analysis I.8. Comparison I Pre-operative traction versus no traction, Outcome 8 Fracture fixation failure. Review: Pre-operative traction for hip fractures in adults

Comparison: I Pre-operative traction versus no traction

Outcome: 8 Fracture fixation failure

\begin{tabular}{|c|c|c|c|c|}
\hline \multirow[t]{2}{*}{ Study or subgroup } & Traction & No traction & \multirow{2}{*}{$\begin{array}{c}\text { Risk Ratio } \\
\text { M-H,Fixed,95\% Cl }\end{array}$} & Risk Ratio \\
\hline & $\mathrm{n} / \mathrm{N}$ & $\mathrm{n} / \mathrm{N}$ & & M-H,Fixed,95\% Cl \\
\hline \multicolumn{5}{|l|}{ I All fractures } \\
\hline Jerre 2000 & $14 / 54$ & $9 / 56$ & + & $1.61[0.76,3.41]$ \\
\hline \multicolumn{5}{|c|}{2 Intracapsular fracture } \\
\hline Jerre 2000 & $11 / 26$ & $9 / 29$ & + & $1.36[0.67,2.76]$ \\
\hline \multicolumn{5}{|c|}{3 Extracapsular fracture } \\
\hline Jerre 2000 & $3 / 28$ & $0 / 27$ & 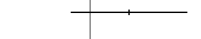 & $6.76[0.37,124.98]$ \\
\hline
\end{tabular}

Analysis I.9. Comparison I Pre-operative traction versus no traction, Outcome 9 Length of operation (minutes).

Review: Pre-operative traction for hip fractures in adults

Comparison: I Pre-operative traction versus no traction

Outcome: 9 Length of operation (minutes)

\begin{tabular}{|c|c|c|c|c|c|c|c|}
\hline \multirow[t]{2}{*}{ Study or subgroup } & Traction & \multicolumn{3}{|c|}{ No traction } & \multirow{2}{*}{$\begin{array}{l}\text { Mean Difference } \\
\text { IV,Fixed,95\% Cl }\end{array}$} & \multirow[t]{2}{*}{ Weight } & \multirow{2}{*}{$\begin{array}{r}\text { Mean Difference } \\
\text { IV,Fixed,95\% Cl }\end{array}$} \\
\hline & $N$ & Mean(SD) & $\mathrm{N}$ & Mean(SD) & & & \\
\hline Resch 2005 & 49 & $53(31)$ & 53 & $59(33)$ & $\boxplus$ & $24.1 \%$ & $-6.00[-18.42,6.42]$ \\
\hline Yip 2002 & 166 & $73.2(34.8)$ & 145 & $69.6(28.2)$ & $T$ & $75.9 \%$ & $3.60[-3.41,10.61]$ \\
\hline
\end{tabular}

Total (95\% CI)

215

198

$100.0 \% \quad 1.28[-4.82,7.39]$

Heterogeneity: $\mathrm{Chi}^{2}=1.74, \mathrm{df}=\mathrm{I}(\mathrm{P}=0.19) ; \mathrm{I}^{2}=43 \%$

Test for overall effect: $Z=0.4 \mathrm{I}(P=0.68)$

Test for subgroup differences: Not applicable

$\begin{array}{cccc}-100 & -50 & 0 & 50 \\ \text { Favours traction } & & \text { Favours no traction }\end{array}$


Analysis I.10. Comparison I Pre-operative traction versus no traction, Outcome 10 Intra-operative blood loss $(\mathrm{ml})$.

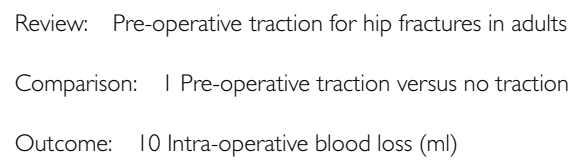

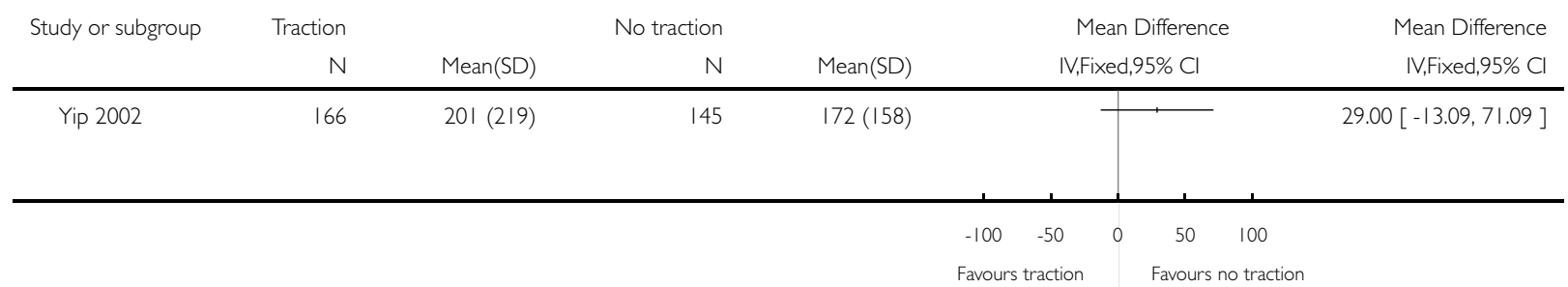

Analysis I.I I. Comparison I Pre-operative traction versus no traction, Outcome I I Length of hospital stay (days).

Review: Pre-operative traction for hip fractures in adults

Comparison: I Pre-operative traction versus no traction

Outcome: II Length of hospital stay (days)

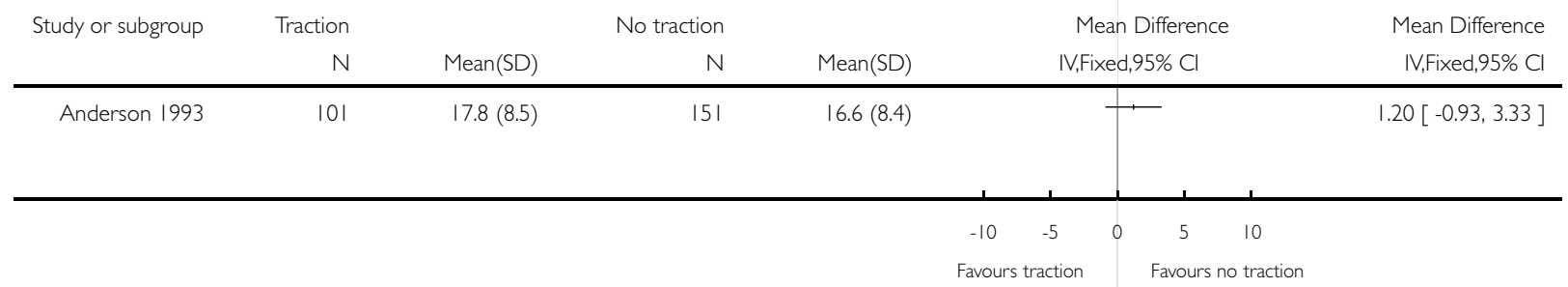


Analysis 2.I. Comparison 2 Traction versus no or 'placebo' traction, Outcome I Pain (VAS) - soon after immobilisation.

Review: Pre-operative traction for hip fractures in adults

Comparison: 2 Traction versus no or 'placebo' traction

Outcome: I Pain (VAS) - soon after immobilisation

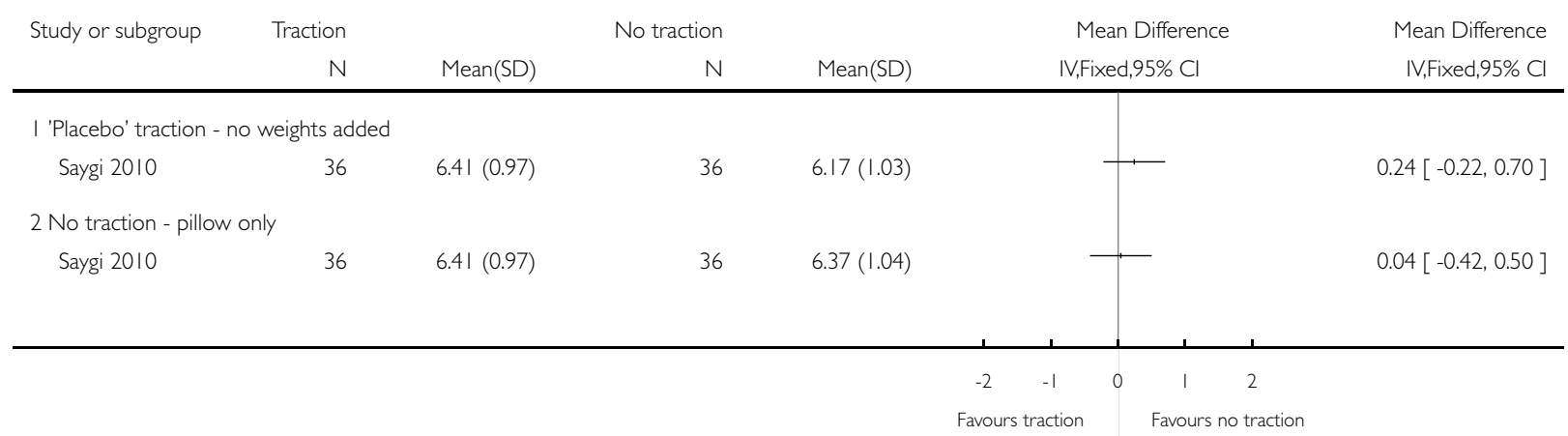

Analysis 2.2. Comparison 2 Traction versus no or 'placebo' traction, Outcome 2 Pain (VAS) - at 12 hours. Review: Pre-operative traction for hip fractures in adults

Comparison: 2 Traction versus no or 'placebo' traction

Outcome: 2 Pain (VAS) - at 12 hours

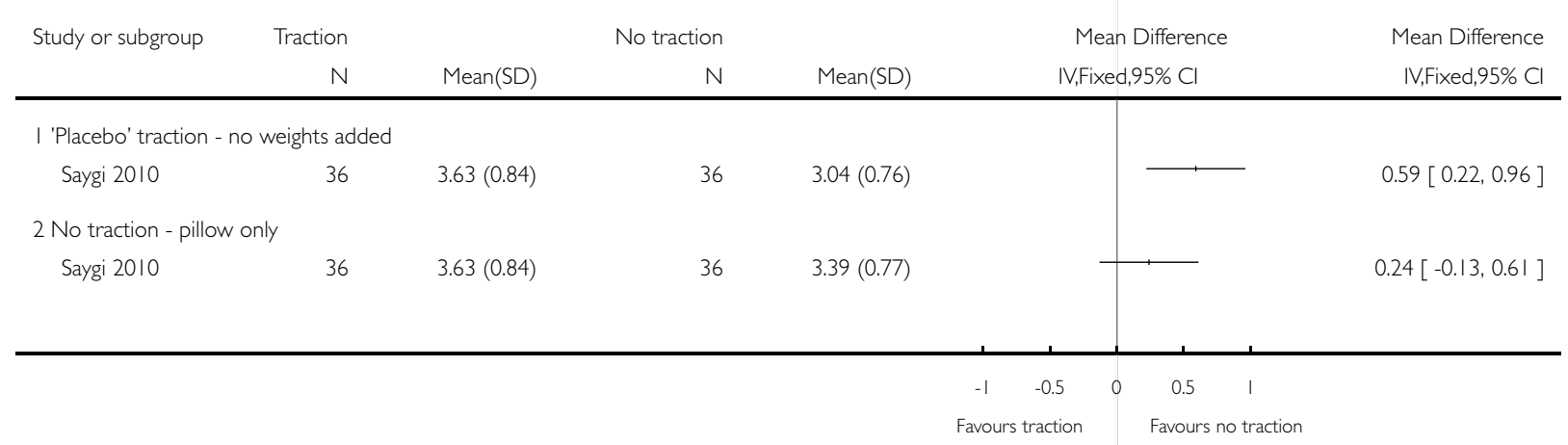


Analysis 2.3. Comparison 2 Traction versus no or 'placebo' traction, Outcome 3 Analgesic use - injections I day.

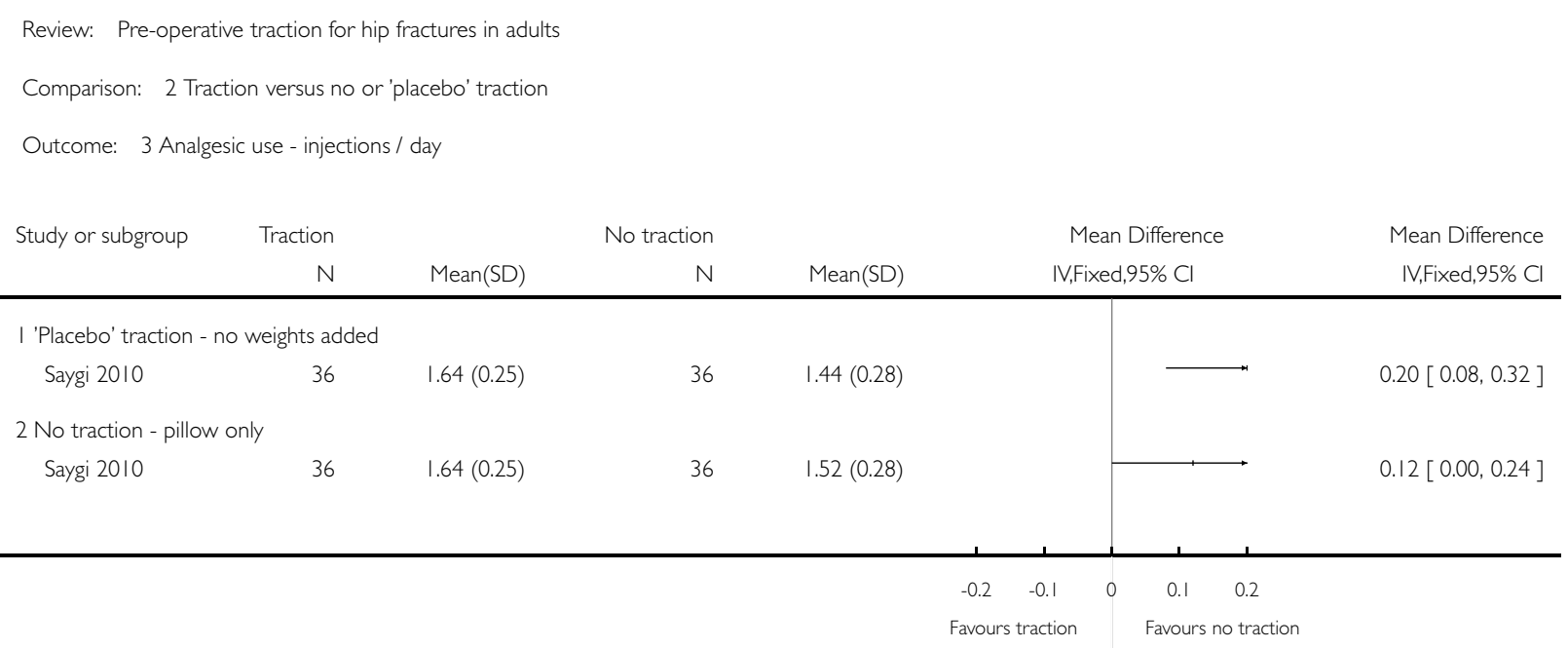

Analysis 3.I. Comparison 3 Skin traction versus skeletal traction, Outcome I Pain soon after traction (Visual Analogue Scale: 0: none to 10: worst imaginable).

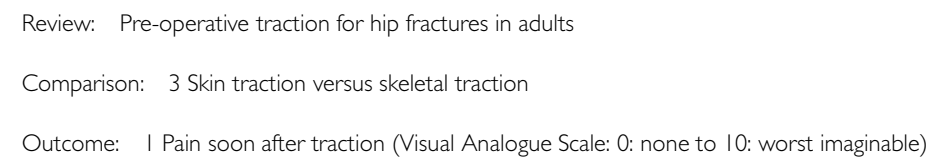

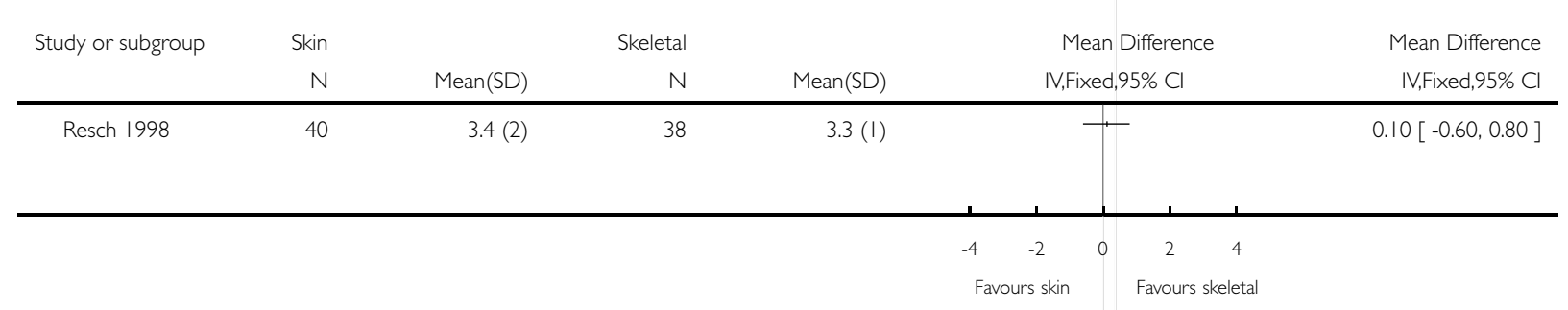


Analysis 3.2. Comparison 3 Skin traction versus skeletal traction, Outcome 2 Analgesic use on ward (number of doses).

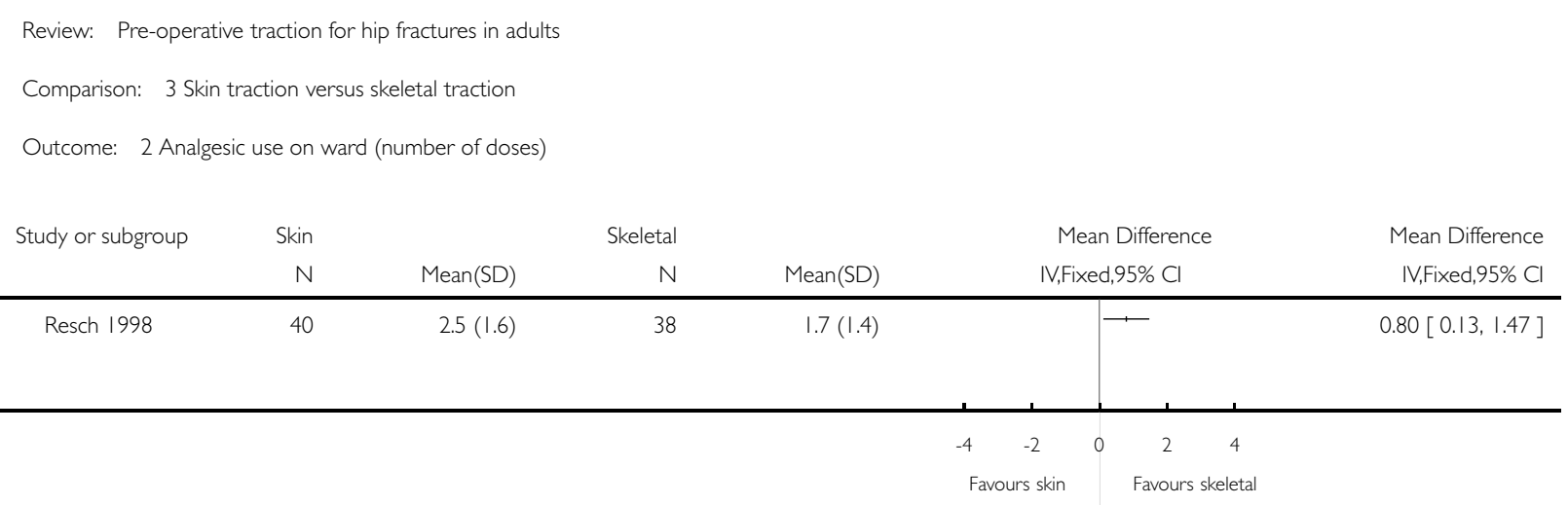

Analysis 3.3. Comparison 3 Skin traction versus skeletal traction, Outcome 3 Length of surgery (minutes).

Review: Pre-operative traction for hip fractures in adults

Comparison: 3 Skin traction versus skeletal traction

Outcome: 3 Length of surgery (minutes)

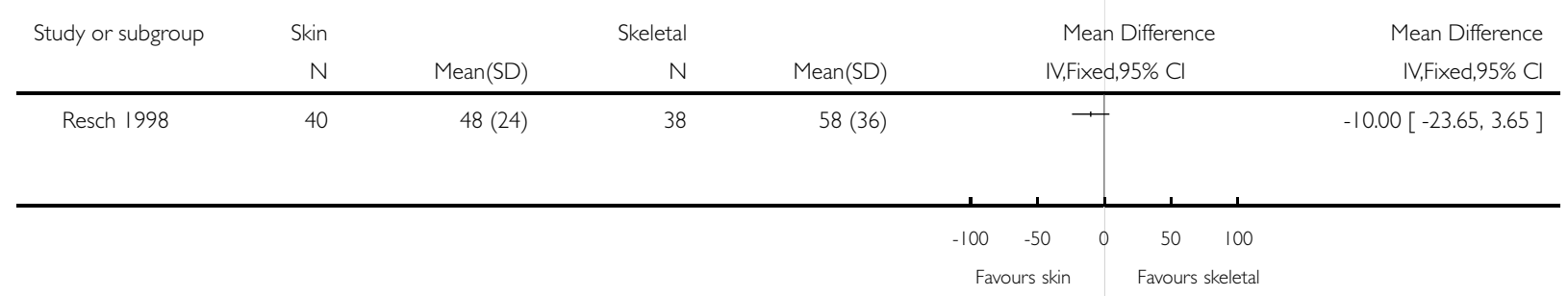




\section{A P P E N D I C E S}

\section{Appendix I. Types of outcome measures listed in previous version of review (issue 3, 2006)}

Data for the following outcome measures were collected where available.

- Degree of pain prior to surgery

- Analgesia use prior to surgery

- Ease of fracture reduction or time taken to reduce fracture

- Length of surgery (in minutes)

- Intra-operative blood loss

- Incidence of pressure sores (also termed pressure ulcers). There are many different pressure sore/ulcer classification systems in use. Typically, the higher the grade the more severe the damage to the tissues. Grade 1 generally represents reddened but unbroken skin (erythema).

- Incidence of thromboembolic complications

- Incidence of other complications (as specified in individual studies)

- Length of hospital stay (days)

- Mortality

- Incidence of fracture non-union

- Incidence of avascular necrosis: aseptic necrosis of bone

- Incidence of other fracture healing complications (as specified in individual studies)

- Patient satisfaction (outcome added in 2006 update)

\section{Appendix 2. Search strategies (with numbers of hits)}

\section{The Cochrane Library (Wiley Interscience) Issue 4, 20 I I}

1. MeSH descriptor Hip Fractures explode all trees (723)

2. femoral OR femur OR hip (11834)

3. fracture* $^{*}(7575)$

4. (\#2 AND \#3) (2982)

5. (\#1 OR \#4) (2982)

6. traction (814)

7. (\#5 AND \#6) (70, of which 46 were in the Cochrane Central Register of Controlled Trials, issue 2, 2011)

\section{MEDLINE (OVID WEB) <1948 to April Week 2 20I I>}

1 exp Hip Fractures/ (14800)

2 ((hip\$ or $(($ femur $\$$ or femoral\$) adj3 (neck or proximal $)))$ adj 4 fracture $\$)$.tw. (14170)

or/1-2 (19221)

Traction/ (5290)

traction\$.tw. (10876)

or/4-5 (13785)

and/3,6 (324)

randomized controlled trial.pt. (303725)

controlled clinical trial.pt. (82147)

10 Randomized Controlled Trials/ (72295)

11 Random Allocation/ (70933)

12 Double Blind Method/ (109282)

13 Single Blind Method/ (14802)

14 or/8-13 (512589)

15 Animals/ not Humans/ (3484143)

1614 not 15 (474933) 
17 clinical trial.pt. (461240)

18 Clinical Trials as topic/ (153412)

19 (clinic\$ adj25 trial\$).tw. (186105)

20 ((singl\$ or doubl\$ or trebl\$ or tripl\$) adj25 (blind\$ or mask\$)).tw. (109987)

21 Placebos/ (29463)

22 placebo\$.tw. (127638)

23 random\$.tw. (510792)

24 Research Design/ (61908)

25 or/17-24 (1046545)

$26 \quad 25$ not $15(965079)$

$27 \quad 26$ not $16(551562)$

28 or/16,27 (1026495)

29 and $/ 7,28(36)$

\section{EMBASE (OVID WEB) $<1980$ to 201 I Week I6>}

1 exp Hip Fracture/ (21741)

2 ((hip\$ or ((femur\$ or femoral\$) adj3 (neck or proximal))) adj4 fracture\$).tw. (17156)

3 or/1-2 (26083)

4 exp Traction Therapy/ (6115)

5 traction\$.tw. (12610)

6 or $/ 4-5(15742)$

7 and $/ 3,6(430)$

8 exp Randomized Controlled trial/ (294051)

9 exp Double Blind Procedure/ (102798)

10 exp Single Blind Procedure/ (14196)

11 exp Crossover Procedure/ (30707)

12 Controlled Study/ (3492488)

13 or/8-12 (3560213)

14 ((clinical or controlled or comparative or placebo or prospective\$ or randomi\#ed) adj3 (trial or study)).tw. (544299)

15 (random\$ adj7 (allocat\$ or allot $\$$ or assign $\$$ or basis $\$$ or divid $\$$ or order $\$)$ ).tw. (134867)

16 ((singl\$ or doubl\$ or trebl\$ or tripl\$) adj7 (blind\$ or mask\$)).tw. (132199)

17 (cross?over\$ or (cross adj1 over\$)).tw. (55917)

18 ( (allocat\$ or allot\$ or assign\$ or divid\$) adj3 (condition\$ or experiment\$ or intervention\$ or treatment $\$$ or therap\$ or control\$ or group\$)).tw. (162106)

19 or/14-18 (816080)

20 or/13,19 (3942447)

21 limit 20 to human (2383844)

22 and $/ 7,21(78)$

\section{CINAHL (EBSCO) (Alert Run Date: 01/04/20 I I)}

S1 (MH "Hip Fractures") (2991)

S2 TX hip* (45080)

S3 TX ( femur* or femoral* ${ }^{*}$ ) and TX ( neck or proximal ) (6177)

S4 S2 or S3 (48033)

S5 TX fractur* (37730)

S6 S4 and S5 (12305)

S7 S1 or S6 (12305)

S8 (MH “Traction") (610)

S9 TX traction (5264)

S10 S8 or S9 (5264)

S11 S7 and S10 (534)

Pre-operative traction for hip fractures in adults (Review)

Copyright ( 2 20II The Cochrane Collaboration. Published by John Wiley \& Sons, Ltd. 


\section{Appendix 3. Previous acknowledgements and contribution of authors}

\section{Acknowledgements (up to 2006)}

We thank Dr Ragnar Jerre and Dr Peter Draper for providing reports of their trials. We thank Prof William Gillespie for his advice at various stages of this review. We thank Mrs Lesley Gillespie for her help in developing and checking the search strategy, for continuing the search for trials for this review and supplying some of the trial reports. We thank Ms Andrea Nelson for supplying one of the trial reports. We would also like to thank the following for useful feedback and help at editorial review of the first version and subsequent updates: Prof Rob de Bie, Dr Marcos Bosi Ferraz, Mrs Lesley Gillespie, Prof William Gillespie, Mrs Frances Healey, Prof James Hutchison, Dr Vicki Livingstone, Prof Rajan Madhok, Ms Leeann Morton, Prof Gordon Murray, Mr Mike Robinson, Ms Lindsey Shaw, Ms Bev Shea, Prof Marc Swiontkowski, Dr Janet Wale and Prof George Wells.

Dr Helen Handoll's work on the first two versions of the review was supported by the Chief Scientist Office, Department of Health, The Scottish Office, UK.

\section{Contributions of authors (up to 2006)}

Martyn Parker initiated and designed the review, usually contacted trialists for further information and compiled the first drafts of the review and most of the subsequent updates. Helen Handoll located the review studies, contacted some of the trialists for further information, checked data entry and critically rewrote the first draft and most of the subsequent updates. All other tasks were shared. Dr Edward To, now in Hong Kong, was involved in the early stages, primarily quality assessment and data extraction of the first version of the review, but is not a named author. Helen Handoll and Martyn Parker are guarantors of the review.

\section{WHAT'S NEW}

Last assessed as up-to-date: 1 July 2011.

\begin{tabular}{l|l|l}
\hline Date & Event & Description \\
\hline 6 October 2011 & New search has been performed & $\begin{array}{l}\text { In this (the eighth) update, published in Issue 12, 2011, } \\
\text { the search for trials was extended to April 2011. The only } \\
\text { newly identified study (Saygi 2010) was included. Risk of } \\
\text { bias assessment replaced the former assessment of method- } \\
\text { ological quality. Various other changes were made in line } \\
\text { with recommendations in the Cochrane Handbook. The } \\
\text { conclusions were strengthened }\end{array}$ \\
\hline 6 October 2011 & New citation required and conclusions have changed & $\begin{array}{l}\text { A new author has been included on the byline. } \\
\text { The title has been changed for consistency with other titles } \\
\text { on hip fractures. The previous title was: 'Pre-operative } \\
\text { traction for fractures of the proximal femur in adults' } \\
\text { The conclusions were changed to give a greater empha- } \\
\text { sis on clinicians needing to provide the evidence for any } \\
\text { continuing use of pre-operative traction }\end{array}$ \\
\hline
\end{tabular}




\section{H I S T O R Y}

Protocol first published: Issue 3, 1996

Review first published: Issue 3, 1997

\begin{tabular}{l|l|l}
\hline Date & Event & Description \\
\hline 12 September 2008 & Amended & Converted to new review format. \\
\hline 19 May 2006 & $\begin{array}{l}\text { New citation required but conclusions have not } \\
\text { changed }\end{array}$ & $\begin{array}{l}\text { In the seventh update, published in Issue 3, 2006, } \\
\text { the search for trials was extended to March 2006. } \\
\text { Both newly identified studies were included (Gh- } \\
\text { naimat 2005; Resch 2005). Details of the method of } \\
\text { randomisation for Resch 1998 were included. A ref- } \\
\text { erence to a survey on the use of pre-operative traction } \\
\text { in Dutch hospitals was added. Various changes were } \\
\text { made in line with recommendations in the Cochrane } \\
\text { Handbook and Style Guidelines. There was no change } \\
\text { to the conclusions }\end{array}$ \\
\hline
\end{tabular}

1 August $2004 \quad$ New search has been performed

The sixth update of the review, published in Issue 4, 2004 , included references to commentaries on two trials. Various changes, including that the scores of the individual items of the methodological quality scoring scheme were no longer summed, were made in line with recommendations in the Cochrane Reviewers' Handbook and Style Guidelines. There was no change to the conclusions

\begin{tabular}{|l|l} 
1 May 2003 New search has been performed & $\begin{array}{l}\text { The fifth update of the review, published in Issue 3, } \\
\text { 2003, included one new trial (Yip 2002). An extra } \\
\text { reference for one trial (Rosen 2001) was added. There } \\
\text { was no change to the conclusions }\end{array}$
\end{tabular}

1 November $2001 \quad$ New search has been performed

The fourth update of the review, published in Issue 3, 2001, included a new trial (Rosen 2001). Extra references for one trial (Draper 1997) were added. There was no change to the conclusions

\begin{tabular}{l|l|l}
\hline May 2001 & New search has been performed & $\begin{array}{l}\text { The third update of the review, published in Issue 1, } \\
\text { 2001, included a new trial. Relative risks instead of } \\
\text { Peto odds ratios were presented for dichotomous out- } \\
\text { comes. There was no change to the conclusions }\end{array}$ \\
\hline 1 February $2000 \quad$ New search has been performed & $\begin{array}{l}\text { The second update of the review, published in Issue } \\
2,2000, \text { included a new trial. There was no change to } \\
\text { the conclusions }\end{array}$
\end{tabular}




\section{CONTRIBUTIONS OFAUTHORS}

Helen Handoll initiated this update and with Joseph Queally, updated the Background and Methods sections. Both authors performed independent assessment of risk of bias for all included trials. All three authors assessed and extracted data for the newly included trial. Helen Handoll and Joseph Queally entered data into RevMan and rewrote the review to include the new trial and reporting requirements. All three authors commented on successive drafts and approved the final version. Helen Handoll and Joseph Queally are guarantors of the review.

\section{DECLARATIONS OF INTEREST}

None known.

\section{SOURCES OF SUPPORT}

\section{Internal sources}

- University of Teesside, Middlesbrough, UK.

- Peterborough and Stamford Hospitals NHS Foundation Trust, UK.

\section{External sources}

- No sources of support supplied

\section{DIFFERENCES BETWEEN PROTOCOL AND REVIEW}

Most of the changes to methods reflected the uptake of new methodology and reporting as described in the Handbook (Higgins 2008b). These include risk of bias assessment and more explicit reporting of data analysis and collection. Types of outcome measures have been revised to define primary and secondary outcomes. 


\section{N DEX TERMS}

\section{Medical Subject Headings (MeSH)}

*Traction; Femoral Fractures [surgery]; Hip Fractures [*surgery]; Preoperative Care; Randomized Controlled Trials as Topic

\section{MeSH check words}

Adult; Humans 